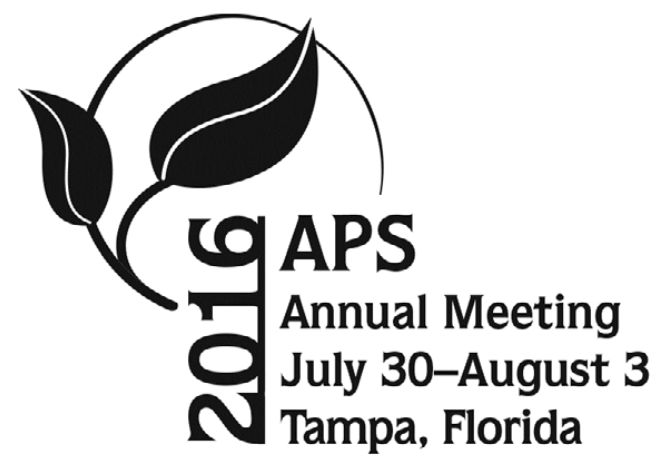

\title{
2016 APS Annual Meeting Abstracts of Special Session Presentations
}

The abstracts are published for citation purposes. They were not reviewed by the Phytopathology Editorial Board and were not edited by the APS editorial staff. Please send questions or comments to aps@scisoc.org. http://dx.doi.org/10.1094/PHYTO-106-12-S4.164

(C) 2016 The American Phytopathological Society

Introduction: The importance of dispersal in botanical epidemics L. MADDEN (1)

(1) Ohio State University, U.S.A.

The spatio-temporal dynamics of plant diseases depend on dispersal, the movement of inoculum from where it is produced to where it is deposited. There is a long history of dispersal research by epidemiologists, with pioneering contributions by Philip Gregory, James Hirst, and others in previous generations, and by the current symposium speakers in today's scientific generation. Dispersal is a physical process (spore removal, transport, and deposition) superimposed on a biological process (spore production, survival of transported spores, infection efficiency of deposited inoculum, latent and infectious periods). Moreover, dispersal requires observations at multiple locations, by definition, and the locations may be (greatly) separated in time and space. These conditions result in huge challenges in conducting research, and most plant pathologists have not taken the challenge. Yet, one clearly needs to account for dispersal in empirical research and in modeling. A theoretical epidemic model will be used to show the general influence of dispersal on temporal disease increase and the rate of disease spread in space. The relevant model component is the contact distribution, the probability of a spore originating at one location (say, where it was produced) coming in contact with a host individual at another location $s$ distances units away, where it may cause infection. Physics is needed to fully define this contact distribution.

Dispersal of Pseudoperonospora cubensis: Basis for Forecasting Cucurbit Downy Mildew Epidemics P. OJIAMBO (1)

(1) North Carolina State University, U.S.A.

In the United States, Pseudoperonospora cubensis, the causal agent of cucurbit downy mildew, is largely thought to overwinter in subtropical areas in southern Florida where mild winters allow for year-round survival of its host. Thus, epidemics in northern states, annually depend on the dispersal of sporangia from the south during periods of strong southerly winds. To facilitate forecasting of initial outbreaks, the Cucurbit ipmPIPE Forecasting system integrates information on known disease sources, outputs from trajectories of sporangia transport, weather conditions along trajectory pathways and host availability, to predict the risk of disease outbreak. The Lagrangian particle dispersion model FLEXPART is used to calculate long-range and mesoscale dispersion of sporangia from known sources. The FLEXPART has been modified to account for survival of $P$. cubensis sporangia during aerial transport. This modification has involved inclusion of a multiplier factor described by an exponential decay model relating sporangia survival to cumulative solar radiation dose during dispersal. The source strength input into the FLEXPART model now accounts for disease severity at the source and this has resulted in better estimates of the standing crop of sporangia that can escape and be available for dispersal. Incorporating of information on biology of $P$. cubensis in the dispersal framework has resulted in realistic forecasts of disease outbreaks in the eastern United States.

Physical aspects of Dispersal of Spores of Plant Pathogens

D. Aylor (1)

(1) Connecticut Agricultural Experiment Station, U.S.A.

Spore dispersal involves a series of interconnected biophysical processes, minimally described as take-off, transport, and deposition. Involved are many detailed fluid-particle interactions taking place on length scales ranging from millimeters to hundreds of kilometers. Principles of fluid engineering are used to quantify the motion of spores as they escape the viscous boundary layer near plant surfaces, move through the roughness sublayer, and escape into the convective boundary layer where they can be transported to nearby and distant crops. The initial stages of dispersal occur in a region of highly inhomogeneous turbulence dominated by intermittency. A Lagrangian simulation framework is adapted to examine the journey of a spore during the course of its flight: first as it is released a few millimeters into the air, then as it escapes from the ground cover canopy via turbulent transport, until it is deposited on an infection site. During this journey, we will address the following questions: Which details of the model are most important to dispersal and which of them can be parameterized more simply? When is it necessary to incorporate highly detailed temporal information, when is it sufficient to simply use time-averaged data, and what is the time scale for this averaging? Simplifications used to model spore dispersal will be highlighted to stimulate discussion about where models can be improved, both theoretically and practically.

Simulation modeling and mitigation of climate change effects on generational migrations of a crop pest: Fall armyworm (Spodoptera frugiperda) J. WESTBROOK (1), R. Nagoshi (2), R. Meagher (2), S. Fleischer (3), S. Jairam (4)

(1) USDA-ARS, U.S.A.; (2) USDA-ARS, U.S.A.; (3) Pennsylvania State University, U.S.A.; (4) Self-employed, U.S.A. 
The fall armyworm (Spodoptera frugiperda) is a pest of tropical origin that cannot survive extended periods of freezing temperature, but must migrate northward each spring if it is to re-infest cropping areas in temperate regions. Genetic analyses have characterized northward migratory pathways from distinct winter-breeding regions in Texas and Florida, but knowledge is lacking on atmospheric influences on timing, distance, direction, and intensity of migratory flights. We estimated daily growth of corn plants and fall armyworm populations, and simulated generational migration of fall armyworm populations using the HYSPLIT (Hybrid Single Particle Lagrangian Integrated Trajectory) atmospheric dispersion model. Model simulations identified regions of overlapping immigrant populations from Texas and Florida and of populations that predominately developed from single natal sources. Reducing migrating populations in overwintering areas and successive immigration zones (known as stepping-stone nurseries) will help lower the pest status of this insect. One areawide management strategy being tested replaces a traditional ground cover plant species that is a good larval host with one that is a poor host plant. The results contribute to knowledge of fall armyworm population ecology on a continental scale, and will aid in the prediction, interpretation, and mitigation of insect migration influenced by climatic change and modified agronomic practices.

A physically-based theoretical model of spore deposition for predicting spread of plant diseases

M. Chamecki (1), S. Isard (2)

(1) University of California, Los Angeles, U.S.A.; (2) Penn State University, U.S.A.

A physically-based theory for predicting spore deposition downwind from an area source of inoculum is presented. The modeling framework is based on theories of turbulence dispersion in the atmospheric boundary layer and applies only to spores that escape from plant canopies. A "disease resistance" coefficient is introduced to convert the theoretical spore deposition model into a simple tool for predicting disease spread at the field scale. Results from the model agree well with published measurements of Uromyces phaseoli spore deposition and measurements of wheat leaf rust disease severity. The theoretical model has the advantage over empirical models in that it can be used to assess the influence of source distribution and geometry, spore characteristics, and meteorological conditions on spore deposition and disease spread. The modeling framework is refined to predict the detailed twodimensional spatial pattern of disease spread from an infection focus. Accounting for the time variations of wind speed and direction in the refined modeling procedure improves predictions, especially near the inoculum source, and enables application of the theoretical modeling framework to field experiment design.

Nano material development, industry technology and status, safety approvals for use as fungicides/bactericides S. SANTRA (1), S. Santra (1)

(1) University of Central Florida, U.S.A.

Copper $(\mathrm{Cu})$ bactericides/fungicides are aggressively used in the agriculture industry in the U.S and worldwide on many crops. There is an increasing concern of $\mathrm{Cu}$ accumulation in field soil and $\mathrm{Cu}$ leaching potential into the surrounding ecosystem. Moreover, development of bacterial resistance to $\mathrm{Cu}$ is a serious concern. While there are no effective alternatives to $\mathrm{Cu}$, strategies for improving the efficacy using nanotechnology is a possibility that is minimally explored. To improve efficacy, we developed and characterized mixed valence (MV) $\mathrm{Cu}$ loaded silica nanogel and core-shell (C-S) $\mathrm{Cu}$ nanoparticle material. It is hypothesized that MV Cu system, specifically enriched with $\mathrm{Cu}(0)$ and $\mathrm{Cu}(\mathrm{I})$ will exhibit enhanced antimicrobial efficacy over traditional $\mathrm{Cu}$ (II) compounds. In another design, an inert particulate silica core was coated with a shell of MV-Cu loaded silica nanogel to produce the $\mathrm{C}-\mathrm{S} \mathrm{Cu}$. MV-Cu and C-S Cu served as a combination of soluble and insoluble $\mathrm{Cu}$ compounds. Both materials were non-phytotoxic and exhibited comparable rainfastness against industry control Kocide 3000 when tested in vitro. The minimum inhibitory concentration values for the MV Cu and C-S $\mathrm{Cu}$ formulations were found to be significantly lower than the Kocide ${ }^{\mathbb{}} 3000$ control. This presentation will focus on the development of MV-Cu and C-S $\mathrm{Cu}$ bactericide formulations and challenges towards developing a commercially-viable $\mathrm{Cu}$ formulation and approaches to minimize regulatory challenges.

Advanced copper and zinc nanomaterials for management of bacterial canker of citrus

E. JOHNSON (1), M. Myers (2), K. Gerberich (1), S. Santra (3), J. Graham (1)

(1) University of Florida, U.S.A.; (2) University of Florida, U.S.A.; (3) University of Central Florida, U.S.A.

Bacterial plant pathogens are notoriously difficult to control. Copper is effective as a surface protective film but does not move systemically without risk of phytotoxicity. Best management of copper is spray application to fruit and foliage, however, optimum coverage along with frequent reapplication is required because the protective film is broken as tissues expand. Dependence on copper has led to bacterial resistance and accumulation of phytotoxic levels of copper in agroecosystems. Due to these drawbacks, new bactericides with alternative modes of action are needed to replace or rotate with copper. Nanomaterials, if properly designed with agricultural economics in mind, can provide new modes of action with copper equivalent or better efficacy. Nanomaterials also provide the possibility of systemic activity depending on particle size and composition. Using citrus canker, caused by Xanthomonas citri subsp. citri, as a model system, multiple new bactericides have been validated as equivalent or better than traditional copper formulations for canker control. At least three modes of action have demonstrated efficacy including a nano-copper formulation, fixed quaternary ammonium, and both particle and film forming zinc nanomaterials. Development of multiple modes of action offers the potential for resistance management of bacterial targets in control of local lesion diseases and potential for systemic activity.

\section{Advanced Nanomaterials for Management of Bacterial Spot of Tomato}

A. STRAYER-SCHERER (1), Y. Liao (1), I. Ocsoy (2), M. Young (3), W. Tan (4), S. Santra (5), J. Jones (1), M. Paret (6) (1) Department of Plant Pathology, University of Florida, Gainesville, FL, U.S.A.; (2) Department of Analytical Chemistry, Faculty of Pharmacy, Erciyes University, Kayseri, Turkey; (3) NanoScience Technology Center and Burnett School of Biomedical Science, University of Central Florida, Orlando, FL, U.S.A.; (4) Department of Chemistry, University of Florida, Gainesville, FL, U.S.A.; (5) Burnett School of Biomedical Sciences, NanoScience Technology Center and Department of Chemistry, University of Central Florida, Orlando, FL, U.S.A.; (6) Department of Plant Pathology, North Florida Research and Education Center, University of Florida, Quincy, FL, U.S.A.

Bacterial spot caused, by Xanthomonas sp., is one of the most damaging tomato diseases worldwide. Due to the limited disease management options, growers rely heavily on copper-based bactericides, which are often ineffective due to the presence of copper-tolerant Xanthomonas strains. Separate studies were undertaken to characterize the antibacterial activity of advanced silver-based (Ag-dsDNA-GO), and copper-based (CS-Cu, MV-Cu, and FQ$\mathrm{Cu}$ ) nanomaterials as alternatives to copper. In vitro, Ag-dsDNA-GO and copper-based nanomaterials at rates as low as $10 \mathrm{and} 100 \mu \mathrm{g} / \mathrm{ml}$, respectively, killed all of the copper-tolerant and -sensitive $X$. perforans cells within $15 \mathrm{~min}$ and 1 to $24 \mathrm{~h}$ of exposure, respectively. In contrast, equivalent rates of metallic copper (up to $1000 \mu \mathrm{g} / \mathrm{ml}$ ) from Kocide 3000 did not significantly reduce copper-tolerant $X$. perforans populations compared to the control at 72 $\mathrm{h}$ of exposure $(\mathrm{P}=0.05)$. In greenhouse studies, tomato plants treated with either $75 \mu \mathrm{g} / \mathrm{ml}$ of Ag-dsDNA-GO, $100 \mu \mathrm{g} / \mathrm{ml}$ of CS-Cu or MV-Cu, or 500 $\mu \mathrm{g} / \mathrm{ml}$ of FQ-Cu prior to artificial inoculation significantly reduced disease severity when compared with copper-mancozeb and water controls $(\mathrm{P}=0.05)$. In a field trial, all of the copper-based nanomaterials significantly reduced disease severity when compared with water controls without a significant impact on yield $(\mathrm{P}=0.05)$. These studies highlight the potential of advanced nanomaterials for the management of bacterial spot of tomato.

Trophic transfer of engineered nano materials: Will the food chain be compromised?

R. DE LA TORRE-ROCHE (1), J. White (1)

(1) Connecticut Agricultural Experiment Station, U.S.A. 
The trophic transfer of engineered nanoparticles from soil through terrestrial food chains was evaluated. Cerium oxide $\left(\mathrm{CeO}_{2}\right)$ and lanthanum oxide $\left(\mathrm{La}_{2} \mathrm{O}_{3}\right)$ bulk and nanoparticles (NP) were added to soil with zucchini, bean or lettuce plants. Leaves were fed to crickets or beetles, which were then fed to secondary consumers (wolf spiders, mantis, or spined soldier bugs). Results from the $\mathrm{CeO}_{2}$ studies showed that Ce content in zucchini and consumers (crickets and spiders) was significantly greater with the NP exposure than bulk metal. Conversely, Ce and La content in beans and lettuce, respectively, did not differ with particle size. Additionally, $\mathrm{Ce}$ transfer to beetles feeding on $\mathrm{CeO}_{2} \mathrm{NP}$ exposed bean leaves was dependent on the growth stage of the beetles and feeding duration; and was biomagnified in the spined soldier bugs that fed on beetle larvae. Although La trophically transferred from crickets to predatory mantises, the NP levels were equivalent to the bulk metal. In another study, the aging effects of CuO on producers (lettuce) and consumers (crickets and lizards) were investigated. Copper accumulation in lettuce leaves and consumers showed no significant difference upon CuO exposure (0$400 \mathrm{mg} / \mathrm{kg}$ ) and aging. Interestingly, expression levels of several target genes involved in $\mathrm{Cu}$ transport suggest that the mechanisms involved in CuO NPs accumulation are differentially regulated as compared to ionic $\mathrm{Cu}$.

Metal oxide nano materials for management of Verticillium wilt on eggplant and Fusarium wilt on watermelon

W. ELMER (1), J. White (1)

(1) The Connecticut Agricultural experiment Station, U.S.A.

Micronutrients in plants play important roles in protecting against disease and stress. We hypothesized that nanoparticle (NP) of certain metal oxides applied foliarly may allow a slow release of ions and/or NP into the phloem for transport to disease-susceptible root tissues. Greenhouse studies compared bulked oxide equivalents to NP of $\mathrm{Cu}, \mathrm{Mn}$, and $\mathrm{Zn}$ for their effect on Verticillium wilt of eggplant and Fusarium wilt of watermelon. Plant weights were highest on plants treated with $\mathrm{NP}$ of $\mathrm{CuO}$. Eggplant root diggestions and analysis revealed that $\mathrm{Cu}$ levels were highest in plants treated with $\mathrm{NP}$ of $\mathrm{CuO}$ when compared to the bulked $\mathrm{Cu}$ equivalent or to untreated plants. Watermelon roots were did not differ in Cu levels. Field studies were conducted with eggplants in soil naturally infested with Verticillium dahliae in 2013 and 2014. Eggplant transplants were foliarly treated once with NP of $\mathrm{CuO}, \mathrm{MnO}$, and $\mathrm{ZnO}$ or their bulked equivalents $(1000 \mathrm{ppm})$ and set into the field plots. Only $\mathrm{NP}$ of $\mathrm{Cu}$ increased the plant canopy and increased yield when compared to controls. Studies in 2015 with increasing rate of $\mathrm{CuO} \mathrm{NP}$ found $500 \mathrm{ppm}$ was optimal. Watermelon field plots were treated with NP $\mathrm{CuO}$, bulked $\mathrm{CuO}$, Kocide 2000, or $\mathrm{Cu}$ octanoate. Plots that received $\mathrm{NP}$ of $\mathrm{CuO}$ produced more yield that any other treatment. These findings suggest the unique size of $\mathrm{NP}$ of $\mathrm{CuO}$ may favor their entry into the plants where they might affect defense mechanisms.

DNA materials integrating nanotechnology and biotechnology

D. LUO (1)

(1) Cornell University, Ithaca, NY, U.S.A.

No Abstract Submitted

Genomics-based Bioforensic Analysis at the National Bioforensic Analysis Center

N. BERGMAN (1)

(1) National Biodefense Analysis and Countermeasures Center, U.S.A.

The identification and characterization of emerging, engineered, or even synthetic biological agents is extremely challenging, and requires an analytical process that is flexible, agent-agnostic, and capable of high resolution. Here we present a genomics-based approach to bioforensic analysis that allows for isolate-level identification of any biological agent, characterization of any sample regardless of complexity, and inferential analysis of DNA sequences to assess both phylogeny and function. This approach includes sample extraction and next-generation sequencing at BSL-2, BSL-3, and BSL-4 as well as bioinformatic analysis using a suite of custom tools and pipelines designed for bioforensics. Several example analyses will be discussed to demonstrate how genomics is applied to different types of bioforensic problems, and to highlight its value in high resolution genotyping, metagenomic analysis, viral discovery, and other applications.

Harnessing WGS for Forensic Analysis: Bioinformatics Pipelines and Data

M. COUGER (1), J. Fletcher (2), W. Schneider (3)

(1) Oklahoma State University, U.S.A.; (2) Oklahoma State University, U.S.A.; (3) USDA ARS, U.S.A.

The security and health of agriculture resources including crop production as well national forest and other plants that metabolize increasing levels of $\mathrm{CO} 2$ in the atmosphere is critical for both the world's food production and environmental conservation. These invaluable resources are under threat from infection by natural established pathogens and emerging infectious agents. To preserve these critical resources and protect them from threats, rapid detection of pathogens, precise serotype identification, and extensive laboratory research aimed at identifying pathogenesis mechanisms and to develop containment/treatment protocols are necessary. Here we discuss emerging developments in the areas of bioinformatics analysis and synthetic biology which aid in the implementation of these goals. These include improvements in assembly algorithms, metagenomic assembly and gene calling software, and genomic wide phylogenetic classification. Synthetic biology developments include the use of CRISPR/Argonaute enzyme systems for targeted sequence specific genomic engineering for study of select agents, gene drive systems allowing cross population genomic modification and engineered heritability in laboratory and wild type microorganisms, de novo synthesis of genomes, and the possibility of use of synthetic amino acids/codon alterations to increase biocontainment of laboratory use of select agents and reduce BSL classification for laboratory strains understudy.

\section{Metabolomics in Microbial Forensics: The example of Citrus Greening Disease in Florida}

J. REYES DE CORCUERA (1)

(1) Department of Food Science \& Technology, University of Georgia, U.S.A.

Citrus Huanglongbing (HLB) is arguably the greatest threat that US citriculture has faced in its history. First detected in Florida in 2005, HLB, presumably caused by the fastidious bacterium Candidatus Liberibacter asiaticus (CLas) has spread to all citrus-producing counties, vectored by a psyllid (Diaphorina citri) that feeds on the phloem from the plant leaves. This disease is the main contributor to the decrease in citrus production which was $50 \%$ lower in 2014/15 than 10 years earlier. Vector and pathogen have been intensively researched in the last 10 years to address the spread, develop management strategies and a cure. Challenges include early detection, understanding movement of the pathogen and the evolution of the disease in planta, developing strategies for treatment, and documenting the impact of the disease in the product quality prior to the complete decline of infected trees. Metabolomics has offered relevant insights into each of these challenge areas. Here we discuss the lessons learned from building a metabolomics laboratory form scratch and reflect on the complexity of the plant-pathogen interactions, the environmental factors that affect its metabolism and our ability to detect CLas.

Whole genome analyses of all known populations of the Select Agent Rathayibacter toxicus

J. STACK (1), M. Arif (2), G. Busot (3), R. Mann (4), S. Liu (2), B. Rodoni (5)

(1) Kansas State University, Manhattan, KS, U.S.A.; (2) Kansas State University, U.S.A.; (3) Kansas State Univesrity, U.S.A.; (4) Victoria Department of Economic Development and Primary Industries, Australia; (5) Victoria Department of Economic Development and Primary Industries, U.S.A.

The U.S. Select Agent Rathayibacter toxicus is a gram positive bacterium with an ecologically complex life history. It has been responsible for the deaths of hundreds of thousands of animals; sheep and cattle in Australia and horses in South Africa. Prior population genetic analyses have identified at 
least five distinct genetic populations in Australia. To better understand this organism, whole genome sequences were generated (PacBio RS II), de novo assembled (HGAP3 assembly pipeline: Hierarchical Genome Assembly Process) and annotated for representative isolates from the five genetically distinct $R$. toxicus populations on four plant species from three geographic regions (Western Australia, South Australia and New South Wales). Illumina Miseq data for all five isolates was used to enhance the accuracy in assembly. Annotation pipelines, Bacterial Annotation System (BASys), Rapid Annotation using Subsystem Technology (RAST), and Integrated Microbial Genomes (IMG-JGI) were used for annotation. Genomes size ranged from $2.346 \mathrm{MB}$ to $2.422 \mathrm{MB}$; the maximum nucleotide difference among genomes was $76,459 \mathrm{bp}$. The annotation projected total number of genes from 2491 to 2598 . A total of 51 RNA genes were identified including, 45 tRNA CDS and 6 rRNA CDS in each genome. Genome structure and character among the five genetic populations will be discussed.

Microbial Forensics Case Study: Applications of Forensic Technology in a Field Outbreak of Salmon Blotch of onion

J. FLETCHER (1), J. Fletcher (2), I. Moncrief (3), U. Melcher (2), A. Gamliel (4), J. Stack (5)

(1) Department of Entomology \& Plant Pathology, Oklahoma State University, Stillwater, OK, U.S.A.; (2) Oklahoma State University, Stillwater, OK, U.S.A.; (3) Harry S. Truman College, Chicago, IL, U.S.A.; (4) Volcani Institute, Bet Dagen, Israel; (5) Kansas State University, Manhattan, KS, U.S.A.

Forensic tools were developed and applied to investigate an actual outbreak, in Israel, of salmon blotch disease of onions, caused by Fusarium proliferatum. A decision tool designed to assist investigators recognize signs of criminal activity at the field was implemented. F. proliferatum was isolated from onions and soil from the affected field, nearby fields and natural vegetation in southern Israel onion production areas, and from onion sets, grown in northern Israel and shipped for planting in southern fields, to test whether the fungus was disseminated on the sets. SSR analyses revealed that fungal populations from onion sets (northern Israel) are genetically distinct from those in southern Israel. F. proliferatum populations from southern field soils are similar to one another and to those from bulbs at each southern field. Further, F. proliferatum isolates from volunteer salt cedars in the onion fields are clonal and indistinguishable from those from the southern field soil and white onion bulbs. The findings suggest that onion sets from northern Israel are not the source of the $F$. proliferatum causing onion salmon blotch in southern Israel. Volunteer weeds, including salt cedar, and previously contaminated field soil could serve as alternative reservoirs for the fungus, from which inoculum could have moved to the onions. This work validated the use of microbial forensic tools, in both laboratory and field settings, for investigation of a plant disease.

Phyllosphere fungal endophyte effects on plant disease are context-dependent

P. BUSBY (1), G. Crutsinger (2), M. Barbour (2), G. Newcombe (3)

(1) Oregon State University, U.S.A.; (2) UBC, Canada; (3) U Idaho, U.S.A.

Manipulative experiments demonstrate that individual fungal leaf endophytes can contribute to plant defense against pathogens. However, whether disease protection depends on species interactions within the leaf microbiome is not well known, particularly for complex microbiomes that exist in nature. We tested whether competition between a leaf rust pathogen and an endophytic mite affects fungal leaf endophyte antagonism of leaf rust disease in Populus. We manipulated competitive interactions between the rust pathogen and the mite by using a suite of Populus genotypes that differ in genetic resistance to the two organisms. We inoculated Populus leaves with fungal leaf endophytes and then evaluated rust disease severity. Endophytes reduced disease severity only in the absence of mite-rust competition, illustrating the importance of competition for plant microbiome function.

Exploitation of microbial symbionts from prairie grasslands for crop enhancement

K. CRAVEN (1), K. Craven (2)

(1) Samuel Roberts Noble Foundation, U.S.A.; (2) The Samuel Roberts Noble Foundation, U.S.A.

Declining reserves of mineral phosphorus and growing economic and environmental costs associated with fertilizer use (and misuse) have necessitated efforts to identify cropping systems and strategies that can be sustained under and low-input strategy. One approach to ameliorate such losses is to utilize microbial symbionts that have evolved to promote plant growth through nutrient and water acquisition as well as reduce plant stress when grown on marginal, low-quality soils. Soils such as these are expected to be tapped to grow cellulosic feedstocks for biofuel production. Here, we describe our efforts to maximize the performance and abiotic stress tolerance of switchgrass, a $\mathrm{C} 4$ grass native to the prairies of northern OK, through microbial symbiosis. Strain discovery combined with the implementation of high-throughput screens for potentially useful traits, have resulted in a manageable number of bacterial and fungal endophytes that we are testing in greenhouse trials. Results to date suggest that both biomass and drought tolerance can be enhanced by a novel type of mycorrhizae and bacteria have been identified that are being tested for phosphorus solubilization, nitrogen fixation and the alleviation of ethylene-induced plant stress.

\section{The role of insect-associated microbes in altering host plant defenses}

C. CASTEEL (1), A. Bak (2), S. Whitham (3)

(1) University of California-Davis, U.S.A.; (2) University of California-Davis, U.S.A.; (3) Iowa State University, U.S.A.

Plants employ diverse responses mediated by phytohormones to defend themselves against pathogens and herbivores. Adapted pathogens and herbivores often manipulate these responses to their benefit. Previously we demonstrated that Turnip mosaic virus (TuMV) infection suppresses callose deposition, an important plant defense induced in response to feeding by its aphid vector (Myzus persicae), and increases aphid fecundity compared to uninfected control plants. We determined that production of a single TuMV protein, NIa-Pro (Nuclear Inclusion a - Protease domain), was responsible for decreased plant defenses through changes in the phytohormone signaling molecule ethylene. Further, we show NIa-Pro reversibly responds to the presence of the aphid vector during infection, relocalizing from the nucleus to the vacuole. Importantly, relocalization is required for NIa-Pro's ability to decrease plant defense and this phenomenon occurs for other potyviruses. Taken together, these results suggest that the virus responds to the presence of the insect vector, promoting insect performance and transmission through host plant changes only when needed, a phenomenon that has not been previously demonstrated for any animal or plant viruses.

\section{The role of microbial communities in the development of the immune competency of plants}

S. HE (1)

(1) Michigan State University, U.S.A.

Microorganisms have a broad spectrum of associations with plants. While select binary interactions have been studied in depth, notably pathogenic interactions and symbiotic nodulation of legumes, little is known about the dynamic functional relationship of a plant and its microbiome. As sessile primary producers rooted in soil, the richest microbial environment on Earth, plants must rely on an intricate innate immune system to recognize and respond to certain microbe-associated molecular patterns (MAMPs) for survival. Plants are constantly exposed to MAMPs in nature, yet the functional impact of this constant exposure remains elusive. To characterize the collective functional impact of the plant microbiome, we developed FlowPots: a unique gnotobiotic system that enables sensitive plant colonization assays and host phenotyping. Using the model host plant Arabidopsis thaliana, we germinate microbe-free seeds in substrate inoculated with various complex soil communities or defined bacterial microcosms. Profiling of the basal transcriptome and hormone quantification reveals compromised expression of immune-associated genes, and a series of immune assays reveals the reduced immunocompetence of gnotobiotic plants, compared to colonized plants. Collectively, our results indicate that the plant microbiome is necessary for normal immune function. 
Evaluation of microbials using comparative genomics and high-throughput assays as a method to reduce product development time S. INCH (1), J. Leder (2), A. Taylor (2), M. Frodyma (2), M. Furlan (2), M. Schulte (2), R. Berka (2), M. Maranta (2), B. Cherry (3), E. Prusinkiewicz (4) (1) Novozymes, U.S.A.; (2) Novozymes, U.S.A.; (3) novozymes.com, U.S.A.; (4) novozymes, Canada

When developing any biocontrol product it is important to correlate lab research to field efficacy. This requires careful planning and design to help minimize false positives that are passed through screens to expensive field trials. Screening is a multistep process starting with in-vitro plate assays followed by growth cabinet and greenhouse disease trials. The positive hits from these experiments are then advanced to the field. Developing highthroughput assays helps to reduce the development time of new products through quicker initial screening processes, and increase the understanding of the potential modes of action. High-throughput experiments using a commercial biocontrol product, Taegro, and other B. amyloliquefaciens strains were developed using comparative genomics and plant phenotyping on the Scanalyzer system. Forty-three $B$. amyloliquefaciens genomes were analysed and compared for genes encoding for antimicrobials. To validate the role of these compounds, leaf disk and in planta assays were developed. Genes encoding key antimicrobial metabolites were either deleted or up-regulated in B. amyloliquefaciens (Taegro). The scanalyzer system was able to discern differences in the levels of biocontrol. Based on the results, it can be concluded that using comparative genomics and high-throughput assays could reduce the chances of false positives, increase the chance of identifying new biocontrol agents, and allow for quicker product release.

Can I use this strain? Legal issues impacting the use of microbial resources and how whole genome sequence may solve them K. McCluskey (1)

(1) Kansas state university, U.S.A.

International treaties impact the use of genetic resources including microbes. The Convention on Biological Diversity (CBD) entered into force in 1993 and any genetic resources described prior to then are considered the shared heritage of mankind. The Nagoya protocol on Access to Genetic Resources and the Fair and Equitable Sharing of Benefits Arising from their Utilization (ABS) is intended to simplify implementation of the CBD and entered into force in October 2014. Both of these mandate that each party (country) should establish national legislation to implement the treaty. Regarding ABS, each party is to establish an ABS Clearing-house to register and provide information. These are easily identified through the CBD at www.cbd.int. Research use is not exempt and any collecting must be done with Prior Informed Consent (PIC) under Mutually Agreeable Terms (MAT). Researchers should be aware that their actions may have impact upon collaborators. Because these international obligations are location based, it is essential to document the geographic range of resources. Because the whole genome sequence of microbial resource can be determined, the geographic distribution of the trait of interest can be identified. If a trait is distributed globally, it should not be the property of one entity. Conversely, if a trait is associated with one unique geographic region or location, benefits from its utilization should return to the country or community of origin.

\section{Modelling landscape-scale spread to inform plant health policy}

N. CUNNIFFE (1)

(1) University of Cambridge, United Kingdom

I introduce a flexible framework to model large-scale spread of disease that can be used to investigate potential management strategies. This model can be - and indeed in the UK already has been - used to inform plant health policy. I introduce the methodology by analysing a counterfactual control of sudden oak death in California. I use that epidemic as a case study illustrating the following - general - questions. How can spread be modelled and parameterised? How quickly must control start for it to be effective? When is an epidemic so large that effective control is impossible? How should local treatment be deployed around infected sites? How does this depend on the available budget and level of risk aversion? Which sites should be targeted for control when there is insufficient resource to treat all infected locations? What is the effect of a budget that changes over time? In practice, when an invading pathogen is first detected, policy makers must necessarily answer similar questions rather quickly, while epidemiological data remains scant. I show how the underlying framework can readily be adapted to new pathogens, integrating over epidemiological uncertainty to make useable predictions. Here I use the example of Chalara ash dieback in the United Kingdom. The real-time modelling results I present were fundamental in setting the UK government's response to this pathogen directly after it was first detected in the UK.

Monitoring spread of Phymatotrichopsis root rot disease in alfalfa fields using aerial imagery

C. MATTUPALLI (1), C. Moffet (2), J. Rogers (1), C. Young (1)

(1) The Samuel Roberts Noble Foundation, U.S.A.; (2) USDA-ARS, U.S.A.

Phymatotrichopsis Root Rot (PRR) caused by the soil-borne ascomycete, Phymatotrichopsis omnivora affects alfalfa stand life. PRR disease typically manifests as circular rings and continuous monitoring of PRR disease sites is essential from a disease management perspective. In summer 2014, an Unmanned Aerial Vehicle (UAV) was utilized to take aerial images of a 48.5 hectare alfalfa hay production field at the Noble Foundation's Red River Farm, Burneyville, OK. The UAV imagery was obtained using a 10 megapixel (MP) RGB (Red/Green/Blue) and 10 MP Near Infrared dual sensor camera mounted on a Vireo UAV. In autumn 2014 and during the 2015 growing season, Very Large Scale Aerial (VLSA) digital imagery was obtained using a 22 MP Canon EOS 5D Mark III mounted on a Dragonfly sport utility aircraft. Images were taken at approximately monthly intervals starting in June and continuing through October during both years. Aerial imagery was validated at monthly intervals in 2015 across five active disease sites by measuring the movement of the disease front at ground level. By the end of the growing seasons, considerable agreement between UAV and ground data was observed for PRR disease front movement. This movement ranged from $2.8 \mathrm{~m}$ for the acquired aerial images and $3.0 \mathrm{~m}$ for ground-based observations. Results from this study show the feasibility of UAVs as a tool for tracking disease spread throughout the growing season.

\section{Crystal ballroom dancing for phytoepidemiological prospecting}

D. ANCO (1)

(1) Clemson University, U.S.A.

Epidemiology has been used to reveal obscured relationships, substantiate supposed claims and provide confidence for management decisions. Its application can increase resource and time efficiency while concurrently decreasing detriments like pesticide resistance and yield loss. At heart, it studies disease-related changes over spacetime. How then, might epidemiology and disease management manifest as time itself changes? Systems-level integrative approaches, advances in detection technologies and -omics studies, statistics in allied fields and Phytobiomes Initiative-inspired work are poised to integrate towards a collective springboard from which future epidemiological directions may spawn. This talk will present model development research by the author, show how it fits into the progression of the discipline and posit portions of the possible future of epidemiology and disease management, including concurrent and lagged systems interactions, process-subcomponent prediction and applicability of non-Gaussian random effect distributions to plant disease epidemic modeling. Ideas will be illustrated through case studies and hypothetical epidemic scenarios in perennial and annual systems. Where applicable, points related to implementing proposed ideas on a practical level will be discussed.

\section{Integrated disease management for optimizing soybean yields and profitability}

H. MEHL (1)

(1) Virginia Tech Tidewater AREC, U.S.A.

Over the past decade, soybean producers have increased inputs, including foliar fungicides, to maximize yields. Typically, fungicide applications are made at beginning pod (R3), but yield responses are inconsistent. One contributing factor may be application of fungicides when disease pressure is low 
and conditions do not favor disease development. A second is the occurrence of fungicide resistant pathogens. Objectives of this work were to 1) develop a weather-based decision aid for foliar fungicide applications in soybean, 2) quantify frequencies of fungicide resistant pathogens, and 3) assess profitability of different foliar fungicide programs. R3 and weather-based fungicide applications were compared at a total of 15 on-farm locations in 2014 and 2015. Dominant foliar diseases were frogeye leaf spot (Cercospora sojina) and Cercospora blight (C. kikuchii). Yield response to fungicide applications was significant in 5 of 15 trials. R3 applications were equal to or better than weather-based applications, but yield response was greatest when weather conditions conducive to disease development occurred within 7 days of R3. Based on a survey of C. sojina populations in Virginia in $2015,25 \%$ of the population had the mutation conferring resistance to QoI fungicides. Implications of environmental conditions and fungicide resistance for cost-effective, sustainable management of soybean foliar diseases will be discussed.

Fungicide stress induces genome mutation in Sclerotinia sclerotiorum

S. EVERHART (1), B. Amaradasa (1)

(1) University of Nebraska, U.S.A.

Exposure to low levels of fungicides may generate stress that results in genomic mutations that may be an important source of variation for clonal populations. We tested this hypothesis using the clonal pathogen, Sclerotinia sclerotiorum. Eight wild-type isolates were exposed to five fungicides with different modes of action: boscalid, iprodione, thiophanate methyl, azoxystrobin and pyraclostrobin. Mycelium was grown on a logarithmic fungicide gradient and sub-cultured from the $50-100 \%$ inhibition zone for 12 consecutive generations. A selection of fungicide-exposed isolates ( $\mathrm{n}=17$ ) showing mutations at SSR loci were selected for further analysis, in addition to pre-exposure $(\mathrm{n}=8)$ and non-exposed control isolates after 12 generations on PDA $(\mathrm{n}=8)$. Amplified fragment length polymorphism (AFLP) analysis was performed using three primers and resulted in a set of 602 polymorphic alleles. Cluster analysis with PCoA and DAPC showed fungicide-treated isolates formed a distinct group from pre- and non-exposed control isolates (PhiPT $=0.151, P=0.001$ ). Dendrograms based on neighbor-joining also supported allelic variation associated with treatment groups, where a single cluster with high bootstrap support (60.7\%) included 12 of 17 fungicide-exposed isolates. Collectively, this work will aid our understanding how nonlethal fungicide exposure may affect genomic variation, which may be an important mechanism for adaptation and evolution of clonal organisms.

Physiological races and genetic diversity of isolates of Phytophthora capsici from Mexican crop production fields

A. CASTRO ROCHA (1), P. Osuna Avila (2), S. Shrestha (3), R. Lyon (4), G. Rodíguez Alvarado (5), S. Fernández Pavía (5), K. Lamour (3) (1) Universidad Autónoma de Ciudad Juárez, Juárez, Chihuahua, Mexico; (2) Universidad Autónoma de Ciudad Juárez, Juárez, Mexico; (3) University of Tennessee, Knoxville, TN, U.S.A.; (4) Colorado State University, CO, U.S.A.; (5) Universidad Michoacana de San Nicolás de Hidalgo, Mexico

Phytophthora capsici is a fungal-like oomycete plant pathogen that causes serious loss to pepper and tomato in Mexico. Our objectives were to characterize isolates from crop production fields for race type and genotypic diversity. Race types were established for five isolates recovered from Aguascalientes, Chihuahua, Guanajuato, Michoacán and Estado de México, towards two sets of differential hosts. Each interaction was tested 20 times. One set of differential hosts contained 26 New Mexico Recombinant Inbred Lines (NM-RILs) of pepper. The NM-RILs revealed two new physiological races. The second differential contained 7 commercial pepper cultivars and differentiated one isolate that was not differentiated using the NM-RIL panel. Genetic diversity was assessed for 81 isolates of $P$. capsici from the Northern and Central regions using a targeted sequencing approach. A total of 33 single nucleotide polymorphism (SNP) sites, previously used for population studies of $P$. capsici in China, were genotyped. Sequence analysis revealed 70 unique and 4 repeated multi locus genotypes. These findings, in total, suggest there is significant genetic diversity in vegetable production regions of Mexico and multiple race types. Implications for survival and spread will be discussed.

Identification of Helianthus accessions resistant to Plasmopara halstedii (downy mildew) and Puccinia helianthi (rust) R. HUMANN (1), T. Gulya (2), M. Acevedo (3), L. Marek (4), J. Jordahl (3), S. Meyer (3), S. Markell (3) (1) North Dakota State University, Fargo, ND, U.S.A.; (2) USDA-ARS Sunflower Research Unit (retired), U.S.A.; (3) North Dakota State University, U.S.A.; (4) USDA-ARS North Central Regional Plant Introduction Station, U.S.A.

Downy mildew (Plasmopara halstedii (Farl.) Berl and de Toni) and rust (Puccinia helianthi Schwein.) are economically important diseases of sunflower (Helianthus annuиs L.) in the Northern Great Plains. Genetic resistance can be an effective tool for managing both diseases, but the identification of new sources of resistance is needed. Historically, a disproportionate amount of resistance genes have been identified in germplasm originating from Texas. The objective of this study is to identify new potential sources of resistance to $P$. halstedii and $P$. helianthi. One hundred eighty-two $H$. annuus and $33 H$. argophyllus accessions originating from Texas were obtained from the USDA North Central Regional Plant Introduction Station and screened to both pathogens in a greenhouse environment. Ninety-three $H$. annuиs and $23 \mathrm{H}$. argophyllus accessions were resistant to commonly detected $P$. halstedii races, of which, 18 H. annuus and three $H$. argophyllus accessions were resistant to highly virulent races. Seventy-one $H$. annuus and 33 H. argophyllus accessions were resistant to commonly detected $P$. helianthi races, of which, $41 \mathrm{H}$. annuus and five $\mathrm{H}$. argophyllus accessions were resistant to highly virulent races. Seven $H$. annuus and three $H$. argophyllus accessions resistant to both pathogens were identified, two of which were among the most resistant accessions to both pathogens.

Tetracycline resistance genes in epiphytic bacteria collected from Pennsylvania stone fruit orchards

S. BARDSLEY CAPASSO (1), K. Peter (2), H. Ngugi (3), M. Jimenez Gasco (1)

(1) The Pennsylvania State University, U.S.A.; (2) The Pennsylvania State University, U.S.A.; (3) Dupont, U.S.A.

In 2012 and 2013, 648 isolates of epiphytic bacteria were collected from 8 commercial stone fruit orchards in PA. These bacteria were identified and screened for the incidence of tetracycline resistance genes, $\operatorname{tet}(\mathrm{A}), \operatorname{tet}(\mathrm{B})$, and $\operatorname{tet}(\mathrm{C})$. The association of management factors, including oxytetracycline use, oxytetracycline application method (e.g., alternate row middle versus complete application), and tree age, with the incidence of tetracycline resistance genes was evaluated. A total of eight bacterial genera were identified and included Pantoea (39.8\%), Xanthomonas (31.9\%), Pseudomonas (15.7\%), Bacillus (6.3\%), Curtobacterium (2.9\%), Staphylococcus (2.6\%), Frondihabitans $(0.6 \%)$, and Rahnella $(0.3 \%)$. Tetracycline resistance genes, tet $\mathrm{A}$, tet $\mathrm{B}$, and $t e t \mathrm{C}$, were found in five of the eight sampled orchards. Tet $\mathrm{B}$ was most commonly associated with Pantoea spp. while tet $\mathrm{C}$ was most often found in Pseudomonas spp. The incidence of tetracycline resistance genes significantly differed among the sampled orchards. The number of oxytetracycline applications made in the year of and in the year prior to sample collection was not significantly associated with the incidence of resistance genes, tet $\mathrm{A}, \operatorname{tet} \mathrm{B}$, and $t e t \mathrm{C}$; however, tree age and oxytetracycline application method were. A greater percentage of tetracycline resistance genes were recovered from old trees compared to young trees as well as from trees that had been sprayed with the alternate row middle method.

Searching for genomic signatures of host jumping onto raspberry and strawberry in two Phytophthora sister taxa J. TABIMA (1), B. Kronmiller (2), B. Knaus (3), C. Press (4), I. Zasada (4), B. Tyler (2), N. Grünwald (4), D. Shen (5)

(1) Oregon State University, Corvallis, OR, U.S.A.; (2) Oregon State University, U.S.A.; (3) USDA ARS, Corvallis, OR, U.S.A.; (4) USDA ARS, U.S.A.; (5) Nanjing Agricultural University, China

Contrasting the genomes of sister taxa with narrow but different host ranges provides an ideal system for studying host adaptation. Selection pressures imposed by different hosts are expected to lead to adaptation by gradual divergence of populations and eventual speciation due to reproductive isolation. This process of host-mediated speciation is expected to leave signatures (such as mutations, recombination, indels, or duplications) in the corresponding pathogen genomes. We sequenced and annotated the genomes of two sister species in the plant pathogen genus Phytophthora, P. rubi and P. fragariae, to study which genomic signatures are involved in host adaptation ( $P$. rubi and $P$. fragariae exclusively infects the genus Rubus or Fragariae, 
respectively). Genomes were assembled using SOAPdenovo version 1.05. Gene calling was performed using MAKER. The genomes of $P$. rubi and $P$. fragariae yielded 9,434 scaffolds and an estimated 23,476 genes for $P$. rubi and 8,511 scaffolds and 20,448 genes for $P$. fragariae. Functional annotation showed a similar number of genes involved in different biochemical pathways, such as sugar processing, metabolism, and amino acid synthesis between the two species. Positive selection (dN/dS) was detected for RxLR and CRN effector proteins and five carbohydrate-enzyme genes. Work is ongoing to identify other candidate genes under selection and genomic signatures that may have been involved in the process of speciation via host jumping.

Two symptoms of Cercospora Leaf Blight of soybean suggests two diseases caused by the same pathogen

E. CHAGAS FERREIRA DA SILVA (1), T. Garcia (2), A. Chanda (3), C. Robertson (2), . Lygin (5), R. Schneider (2)

(1) Louisiana State Univ, Agricultural Center, Baton Rouge, LA, U.S.A.; (2) Louisiana State Univ, Agricultural Center, U.S.A.; (3) Department of Plant Pathology, University of Minnesota, U.S.A.; (4) Louisiana State Univ, Agricultural Center, LA, U.S.A.; (5) Department of Crop Sciences, University of Illinois, Urbana, IL, U.S.A.

Considered one of the most devastating soybean diseases in Louisiana, Cercospora leaf blight (CLB) is caused by Cercospora kikuchii, C. flagellaris and C. sigesbeckia. Resistant varieties are not available, and fungicide resistance is widespread. Purple discoloration of leaves exposed to sunlight and leaf blight are the main symptoms of CLB. It is currently assumed that CLB starts with leaf purpling (thought to be a direct accumulation of cercosporin), and leaves become blighted as the disease progresses. Our observations in Louisiana suggested that these symptoms are not correlated. The objective of this work was to examine the relationship between the two CLB symptoms as well as their relationship with fungal growth, cercosporin and flavonoid concentrations $=$ in leaves. Four soybean varieties were planted at two locations. Results showed a low relationship between the two CLB symptoms in Alexandria and Baton Rouge. The pathogen was detected in all leaves (including symptomless); however, blighted leaves had higher fungal biomass than purple leaves. Cercosporin was not detected in symptomless leaves but was detected in low and high concentrations in purple and blighted leaves, respectively. No anthocyanins were found in any leaves. Glyceollin was detected in higher concentration in the intermediate stages of blight symptoms. These results suggest two modes of pathogenesis, which indicates that the same pathogen causes two distinct diseases.

Shovel-ready trees: Forest Health Initiative a model for rapid development and deployment of disease resistant trees C. NELSON (1), C. Nelson (2), W. Powell (3), S. Merkle (4), J. Carlson (5), M. Staton (6), C. Nairn (7), J. Holliday (8), J. Westbrook (9), L. Georgi (9), F. Hebard (9), T. Zhebentyayeva (10), S. Jeffers (10), P. Sisco (9), J. James (11), A. Abbott (12)

(1) USDA-Forest Service, Southern Research Station, Saucier, MS, U.S.A.; (2) USDA Forest Service, Saucier, MS, U.S.A.; (3) State University of New York, U.S.A.; (4) University of Georgia, U.S.A.; (5) Penn State University, U.S.A.; (6) University of Tennessee, Canada; (7) University of Georgia, U.S.A.; (8) Virginia Tech, U.S.A.; (9) The American Chestnut Foundation, U.S.A.; (10) Clemson University, U.S.A.; (11) Chestnut Return Farm, Canada; (12) University of Kentucky, U.S.A.

The Forest Health Initiative (FHI) was founded to develop and test a model for rapidly responding to invasive forest tree pathogens and pests. The developed model begins with a comprehensive evaluation of the biological and technological options, in both ecologic and social contexts. Once a preferred option or a set of options is determined, an inter-disciplinary research team is formed and funded to complete the work. A test case is being implemented for the restoration of American chestnut (Castanea dentata), where robust resistance is critically needed for two invasive pathogensCryphonectria parasitica $(\mathrm{Cp})$, causative agent of chestnut blight, and Phytophthora cinnamomi ( $\mathrm{Pc})$, causative agent of Phytophthora root rot. Biological research has progressed along two distinct yet integrated lines - marker-assisted hybrid breeding with clonal selection and multiplication, and genetic modification utilizing candidate genes isolated primarily from related chestnut species. Both of these approaches were informed by previous work in transcriptomics and genetic mapping and are currently being supported by QTL- and whole-genome sequencing. We will present and discuss the current results of the biological sciences research of FHI and the prospects for American chestnut restoration and applications in other forest tree systems.

Marker assisted selection opportunities for rust and necrotroph resistance in southern pines

J. DAVIS (1)

(1) University of Florida, Gainesville, FL, U.S.A.

No Abstract Submitted

Shovel-Ready Trees: Novel Strategies for Development of Disease Resistant Woody Plants

J. LEBOLDUS (1)

(1) Oregon State University, U.S.A.

A combination of increasing threats from emerging diseases and long breeding cycles complicate selection of disease tolerant germplasm. Future woody plant crops will require novel approaches to develop host resistance. Recent advances in several key areas (clonal selection, marker assisted modeling, RNA silencing etc.) can facilitate the process and significantly reduce the cost and time needed for development of woody plant host resistance. This session aims to highlight the latest developments and demonstrate the power of these new tools for those working with woody plants.

Fourier-transform infrared spectroscopy for the rapid identification of disease resistant trees

C. VILLARI (1), P. Bonello (2), R. Sniezko (3), L. Rodriguez-Saona (4)

(1) The Ohio State University - University of Georgia, Columbus, OH, U.S.A.; (2) Department of Plant Pathology, The Ohio State University, U.S.A.; (3) USDA Forest Service, U.S.A.; (4) Department of Food Science and Technology, The Ohio State University, U.S.A.

As a consequence of the rapid expansion of international trade, we are witnessing increasing frequency of introductions of alien forest pathogens and insects into North America. Some of these introductions result in establishment of devastating, tree-killing invaders into naïve habitats. In many cases, genetic host resistance is the only solution for protecting naïve trees against invasive agents. However, the current lack of rapid phenotyping tools poses a major obstacle to the use of tree resistance. Here we present the development of a novel technique that can potentially revolutionize the efficiency and timing of selecting genetically resistant trees. Fourier-transform infrared (FT-IR) spectroscopy is a vibrational-based chemical fingerprinting technique that has been recently successfully used for the rapid identification of oaks resistant to sudden oak death prior to infection. In this study we show that FTIR spectroscopy can be used for the rapid identification of resistant trees in other pathosystems as well, such as Port-Orford-cedar / root rot disease, and whitebark pine / white pine blister rust. For both pathosystems, we collected and analyzed plant material that had been previously characterized in terms of resistance to its specific pathogen. Using this technique, resistant and susceptible trees were properly discriminated, and mortality rates or severity of symptoms in the progenies were predicted correctly.

Rapid selection and opportunities for restoration of laurel wilt tolerant Persea species

J. SMITH (1), M. Hughes (2), B. Held (3), R. Blanchette (3), T. Dreaden (4), R. Ploetz (2)

(1) University of Florida, Gainesville, FL, U.S.A.; (2) University of Florida, U.S.A.; (3) University of Minnesota, U.S.A.; (4) USDA-Forest Service, Southern Research Station, U.S.A.

In little more than a decade, laurel wilt caused by Raffaelea lauricola (vectored by Xyleborus glabratus) has spread to nine U.S. states, killing hundreds of millions of redbay (Persea borbonia) trees, altering ecosystems and threatening worldwide avocado production. Typically, ambrosia beetles and their fungal symbionts are not tree killers. LW is unique in that the symbiont of X. glabratus is highly virulent to host trees. Current efforts to manage LW 
focus on systemic fungicides, insect repellents, sanitation. Naturally occurring forests with high mortality ( $>95 \%)$ form LW have been explored for persistent survivor trees. Propagation and subsequent disease screening have been carried out leading to the identification of disease tolerant redbay clones. Mechanisms of tolerance appear to be associated with reduced tylosis and reduced disruption of vascular function. Seedling populations from tolerant clones have been genotyped and are being phenotyped for tolerance to assist restoration efforts. Future research will focus on genomic analyses as well as examinations of how phylogeography influences host susceptibility within the Lauraceae.

Perfect harmony: Improving our understanding of microbial relationships in the turfgrass community J. ROBERTS (1), J. Crouch (2), Z. Carter (3)

(1) University of Maryland, U.S.A.; (2) USDA-ARS, U.S.A.; (3) Eleanor Roosevelt High School, U.S.A.

Turfgrass stands support a diverse community of microorganisms. While diseases provide an idea of pathogenic organisms that can thrive on susceptible hosts, many symbiotic microorganisms often go undetected that could impact plant health. As we embark on new research in the turfgrass phytobiome, many question how changes in the environment impact microbial communities and warrants research. In 2015, research was initiated to examine fungi and bacteria that reside on sod [tall fescue (Festuca arundinaceae L.) and Kentucky bluegrass (Poa pratensis L.)] transported between two locations (NJ to Washington, D.C.) within the northeastern United States. Turfgrass at the U.S. National Mall is being replaced by new sod, but it is unknown what novel microbes might be introduced during the process, and to what extent these non-native organisms may impact the environment. To assess microbial communities, core samples were collected from each site, foliage and root-zone material were separated for analysis of each core, and environmental DNA was extracted from each sample. Illumina sequencing libraries were constructed from adapter-modified PCR amplicons generated from foliar and rhizosphere communities of bacteria (i.e., 16S) and fungi (i.e., ITS). Illumina sequencing of DNA libraries was used to determine specific microbial groups associated with each particular site. Sampling will continue through future growing seasons to assess long-term microbial community development.

Impacts of turf management practices on the soil microbiome

J. CROUCH (1), C. Schmid (2), J. Hempfling (3), J. Murphy (2), B. Clarke (2), L. Beirn (2)

(1) USDA-ARS, U.S.A.; (2) Rutgers University, U.S.A.; (3) Rutgers University, Canada

Golf course putting greens are unique, input-intensive environments that require regular fertility and pest management inputs to maintain suitable playing conditions. Little is known about how these practices impact the resident microbial communities. The objectives of this research were to use nextgeneration sequencing to examine the resident microbial communities inhabiting the soil of annual bluegrass (ABG) putting green turf, and to identify how nitrogen and potassium fertilization impacts the diversity and abundance of these communities. A diverse array of microorganisms were present, encompassing $>50$ phyla and representing hundreds of species of archaea, bacteria, and fungi. Potentially beneficial microorganisms, such as antibiotic producers, possible biocontrol agents, mycorrhizal species, and nitrogen fixers were abundant. Fertilization did not reduce microbial diversity, but did alter microbial abundance. Specifically, changes associated with fertility treatments were limited to $7 \%$ of the archaea/bacteria and $23 \%$ of the fungal communities. Seasonality also influenced microbial community composition, with samples collected in warmer months displaying similar species abundance. The research described here provides the first metabarcode-based assessment of the vast microbial community residing in the soil of ABG putting green turf, and will help facilitate future research examining how these microorganisms influence the health and function of this system.

\section{Is organic golf course management a hole in one?: Using microbial analysis to evaluate the turf phytobiome under different management} strategies

E. ALLAN-PERKINS (1), D. Manter (2), G. Jung (3)

(1) University of Massachusetts, U.S.A.; (2) USDA ARS, U.S.A.; (3) University of Massachusetts Amherst, U.S.A.

Microbial communities of annual cropping systems are well-studied, however understanding of perennial turf phytobiomes, despite being the largest irrigated crop in the United States is in its infancy. There is increasing interest in more sustainable turf management practices to encourage beneficial microbial communities aimed at producing high quality turfgrass. Our objective was to determine differences in microbial communities under different management types, intensities, and seasons on golf courses. Soil and thatch samples were collected from an organic and a conventional course in two seasons for two years from all three management areas (roughs, fairways, and putting greens) to represent different management intensities. Bacterial and fungal communities were assessed by qPCR and 454 pyrosequencing of $16 \mathrm{~S}$ and $18 \mathrm{~S}$ rDNA. Species diversity, evenness, and family composition were compared and additionally metabolic profile was analyzed for the bacteria. Fungal abundance was lowest on all putting greens and bacteria that metabolize synthetic pesticide products were highest on the conventional course. Few turf pathogens were identified in the soil samples, however qPCR suggests the thatch may be a reserve area for these organisms. The results of this study provide insight into the turfgrass phytobiome of golf courses, which will help in developing alternative management practices for turf practitioners and directing more targeted research projects.

\section{Microbiome under Turfgrass: Diversity, Abundance and Ecological Functions}

W. SHI (1), W. Shi (1)

(1) North Carolina State University, U.S.A.

Turfgrass is a highly managed ecosystem subject to frequent fertilization, mowing, irrigation, and application of pesticides. Management practices may create a perturbed environment for soil microbial community, the dominant engine that drives carbon, nitrogen and other nutrients throughout the complex plant-soil-atmosphere continuum. To better understand the impacts of turfgrass management, we used a suite of biochemistry, process-level and molecular biology techniques to examine the diversity, abundance and ecological functioning of soil microbial community in a turfgrass chronosequence. Our results indicate that a diverse and abundant microbial community can be achieved and maintained in turfgrass ecosystems. Shifts in soil microbial community structure are primarily attributed to turf establishment rather than the length of turfgrass management.

\section{Private sector career paths with insights for preparation}

\section{MCDUFFEE (1)}

(1) Valent USA Corporation, U.S.A.

Multiple career paths exist for those who are interested in a career in the private sector. Landing a position doing work similar to your studies would be ideal, but is often not the case. The pace and scope of your work may alter based on your assignment, position or career changes. The roles of individuals in R\&D, regulatory, marketing and sales depend on one another and often the lines between them are blurred. This presentation will view a plant pathologist from each of these positions and see how their training has benefitted them. A strong foundation in plant pathology can lead to a successful career which involves one or all of these aspects of a private sector career.

Developing soft skills? What is the Private Sector looking for?

C. GALLUP (1), C. Gallup (1)

(1) Dow AgroSciences, U.S.A.

The agricultural industry diligently works to identify top talent across a broad range of disciplines and specific expertise for careers in crop protection. Despite this broad range of expertise, all hiring managers look for a shared core of demonstrated soft skills. Soft skills are character traits and 
interpersonal skills that characterize a person's relationships with other people in the workplace. "Demonstrated" is a key term: In a very short resume/CV and interview, how can you show that you can effectively lead workgroups, communicate with diverse audiences, use creativity to accomplish goals, or have the interpersonal skills to deal with conflict with a positive outcome? In this presentation, we will discuss what soft skills are, why they're important to hiring managers, how they influence success in the workplace, and how to demonstrate that you have what it takes to succeed.

Technical skills relevant for industry positions: Your research project \& beyond

R. GOSWAMI (1), R. Goswami (2)

(1) Delaware State University, U.S.A.; (2) Delaware State University, U.S.A.

Research and development in an industrial setting, though based on the same principles that you learn during your degree program, is conducted in an environment driven by goals and challenges that differ from those faced in a typical academic situation. These make the emphasis on requirements and competence a little different than what you may expect. This presentation will highlight skills/experiences that will make you more competitive for positions in industry. It will also provide suggestions of resources/options available for gaining such experiences, and propose strategies that will allow you to integrate relevant experience into your research project or degree program.

\section{How to ace an industry interview}

E. TEDFORD (1), E. Tedford (2)

(1) Syngenta, U.S.A.; (2) Syngenta, U.S.A.

Acing the interview is easy, right? Not so fast. Remember job interviews are all about making the best matches of people and company. The company needs to know you are the right fit, and you need to know if the company is right for you. You need to research the job and prepare for the interview, anticipate questions, and follow up. However, interviews in Industry are often much different from academic interviews. More often they are behavioral interviews instead of traditional. So you might not be asked one question about your beloved research. Behavioral interviews are based on the theory that past performance is the best indicator of future behavior. Therefore these interviews focus on questions that probe specific past behaviors, such as: "tell me about a time where you confronted an unexpected problem," or "tell me about an experience when you failed to achieve a goal". Job-seekers need to prepare for these interviews by recalling scenarios that fit these types of behavioral-interviewing questions. So you must prepare for a behavioral interview in addition to a traditional one. This presentation will address some of the most critical things that you can do to prepare yourself to ace an industry interview.

\section{Navigating the job offer \\ E. OYARZABAL (1), E. Oyarzabal (1) \\ (1) Monsanto, U.S.A.}

You just received a job offer. What salary, insurance, time off, and flexibility are you being offered? If you accept the offer now, when can you renegotiate? How much leverage do you have to counter the offer? They've clearly interviewed other people, so if you counter, are they going to walk away? Learn about the motivations behind an offer, the leeway you have to negotiate, and how this is changing. This seminar will analyze these questions and offer negotiation tips from an industry perspective.

\section{The Road to Perdition: The process from detection of exotic pests to regulatory action C. MAROON-LANGO (1), E. Podleckis (1) (1) USDA APHIS PPQ, U.S.A.}

APHIS' Plant Protection and Quarantine (PPQ) program safeguards U.S. agriculture and natural resources against the entry, establishment, and spread of economically and environmentally significant pests, and facilitates the safe trade of agricultural products. A key component of this effort is the identification of pests. PPQ's National Identification Services (NIS) coordinates the identification of plant pests in support of USDA's regulatory programs. NIS categorizes identified pests based on their presence and distribution in the U.S., and their economic importance. NIS collaborates with scientists who specialize in various plant pest groups. These scientists are stationed at a variety of institutions around the country. Accurate and timely identifications provide the foundation for quarantine action decisions. Once identified, pests are subjected to a preliminary screening to determine whether the pests meet the internationally defined criteria for a quarantine pest or regulated non-quarantine pest. The regulatory significance of pests is further refined to determine if they are "actionable" at U.S. ports of entry. Once the quarantine and/or action status of a pest is established, APHIS can develop import requirements for host commodities and/or determine appropriate regulatory responses to any detections of the pest in the United States. This presentation describes the process and policy decisions from detection to policy determinations for exotic pests.

\section{Impact on industry's imports and exports of a pest being listed}

S. THOMAS (1)

(1) Monsanto, U.S.A.

The vegetable seed industry is global in nature. It is common to produce seeds in one country, process in another then deliver them to growers all over the world. The movement of seeds is regulated in that phytosanitary certificates are required for these country to country movements. Frequently, additional declarations (e.g., the lot has been tested and found free of a pathogen) are required as part of the phytosanitary certificate process. The challenge that the industry faces is the rapid adoption of new declarations by importing countries. Irrespective of the validity of the data to drive the regulation change, the seed industry must meet the country requirement for seed to enter. The International Seed Federation has undertaken an effort to review the declarations to move seed and found that $75 \%$ of them have no scientific basis. This talk will touch on how the industry responds to changes in phytosanitary requirements through partnerships with academic and regulatory personnel to drive science-based decisions to free up trade lanes.

\section{Conducting research on strictly regulated quarantine pathogens and diseases - Huanglongbing, citrus canker, and citrus black spot} T. SCHUBERT (1)

(1) Florida Department of Agriculture and Consumer Services-Division Of Plant Industry, U.S.A.

All too frequently in recent times, severe exotic pathogens have emerged in new environments prompting regulatory responses that can make studying the organisms alone and in association with their host(s) complicated. Three examples in Florida citrus have arisen in the last 30 years (in chronological order canker, HLB and black spot), each affording opportunities to creatively adapt phytosanitary regulation and research to learn more about the disease while simultaneously working to prevent further damage where introduced or jeopardize pathogen-free areas elsewhere. Several principles are taking shape to help meet this dilemma, among them: 1) Trade in the commodity (fresh citrus fruit) has not proven that risky yet. Encroachment apparently happens by other means; 2) Political boundaries confound regulatory efforts that need to reflect biological realities; 3) Time sensitivity associated with most new outbreaks dictates swift and decisive action with adaptive flexibility built into the program; 4) Each stakeholder group (trading partners, producers, packers/shippers, scientists, and consumers) needs to understand as much as possible how a pathogen moves and behaves in various environments and what role each group plays in the regulatory actions necessary to minimize further damage. Effective communication is indispensable 5) Research funding and facilities should proactively acknowledge and accommodate the unique circumstances accompanying an exotic introduction. 
The plant regulatory challenges caused by improved diagnostic techniques combined with globalization

D. Golino (1)

(1) University of California, U.S.A.

Modern diagnostic techniques, most notably high throughput sequencing (HTS), have had far reaching impacts on many aspects of plant regulatory activities around the globe. As the Director of Foundation Plant Services, a center in the National Clean Plant Network (NCPN), my staff and I have struggled to manage our activities in the face of an increasingly complex regulatory environment which often poses seemingly insurmountable barriers to the exchange of plant material between centers, between states, and between companies. The main focus of National Clean Plant Network activities is producing virus screened collections of Specialty Crops including berries, fruit and nut trees, grapevines, hops and roses. The discovery of new viruses in these crops by HTS and the subsequent development of robust polymerase chain reaction (PCR) tests for the newly discovered viruses is causing ripples throughout the distribution chain for important plant material which can be placed in limbo by the detection of previously undetected viruses in collections. In many cases, the biological significance of the virus is unknown and there may be many years between discovery and determination of pathogenicity; this is particularly true for the woody perennial crops which are managed in the NCPN network. Globalization adds its own challenges as information about discoveries moves quickly, often triggering regulatory actions that can stymie long established trade relationships.

A novel transporter and a protein translation component are necessary for fire blight disease development

S. KLEE (1), I. Mostafa (2), S. Chen (2), T. McNellis (1)

(1) Penn State University, U.S.A.; (2) Department of Biology, University of Florida, U.S.A.

Erwinia amylovora causes fire blight, an economically important bacterial disease of rosaceous plants. Characterized pathogenicity factors of $E$. amylovora include the extracellular polysaccharide (EPS) amylovoran and a type III protein secretion system. In a search for novel pathogenicity factors, $\mathrm{Tn} 5$ transposon mutagenesis revealed that $r f b X$ and $y j e K$ are required for $E$. amylovora virulence. $r f b X$, which encodes a putative polysaccharide transporter involved in either EPS or lipopolysaccharide moiety movement across the cell membrane, is part of a two-gene operon along with yibD, which encodes a predicted glycosyltransferase. Surprisingly, deletion of the entire $y i b D r f b X$ operon or $y i b D$ alone did not result in a virulence-defective phenotype. Genetic suppressor screening by transposon mutagenesis of an $r f b X$ deletion strain recovered multiple yibD mutants with a restored virulence phenotype. YjeK is a highly conserved protein providing an essential posttranslational modification of elongation factor $\mathrm{P}$, which catalyzes the first peptide bond formation of certain proteins. iTRAQ proteomics revealed numerous differences between the wild-type and yjeK mutant proteomes, including some related to the pleiotropic mutant phenotype, such as loss of virulence and motility, and increased chemical sensitivity. Our results suggest that $y j e K$ has a broad function, including contribution to survival in the stressful host environment, while $r f b X$ may have a virulence-specific function.

Complete genome sequences of Xanthomonas axonopodis pv. phaseoli and X. fuscans subsp. fuscans generated by long-read sequence technology M. O'LEARY (1), G. Coaker (1), R. Gilbertson (1)

(1) University of California, Davis, U.S.A.

Common bacterial blight, caused by Xanthomonas axonopodis pv. phaseoli (Xap) and X. fuscans subsp. fuscans (Xff), is a globally important disease of common bean. Despite causing identical symptoms, Xap and Xff are genetically and phenotypically distinct species. No race structure exists for common bean, although pathogenic variability has been observed, particularly for Xap. To assess the relationship among these bacteria, five Xap and three Xff isolates representative of global diversity were selected for whole-genome sequencing using the Pacific Biosciences RSII platform. Complete genomes of all eight isolates were $\sim 5 \mathrm{Mb}$, with a single chromosome and one to three plasmids. One plasmid is conserved among all isolates, whereas a second was conserved in the three globally predominant Xap and all Xff isolates. Genomic rearrangements between Xap and Xff isolates are consistent with these representing genetically distinct species. A brown diffusible pigment, produced in culture by Xff strains as the result of secretion and oxidation of homogentisic acid, was associated with a frameshift in the gene encoding homogentisate dioxygenase (hmgA). Deletion of the hmgA from Xap isolates lacking this mutation resulted in brown pigment production, whereas complementation of a Xff isolate with a functional hmgA reduced pigment production substantially. This provides biological evidence that brown pigment production in Xff is due to the lack of a functional hmgA gene.

\section{$O$ antigen functions as a shield during the Xylella fastidiosa-grapevine interaction}

J. RAPICAVOLI (1)

(1) University of California, U.S.A.

Plant host recognition of conserved pathogen-associated molecular patterns (PAMPs) leads to activation of the first tier of the innate immune response, known as PAMP-triggered immunity (PTI). Successful plant pathogens must evade or overcome PTI to establish and cause disease. Suppression of PTI by secreted effector proteins is a well-known strategy employed by many bacterial plant pathogens. Xylella fastidiosa is a xylem-limited bacterium that causes destructive diseases such as Pierce's disease (PD) of grapevine. X. fastidiosa lacks the quintessential Type III secretion system and its suite of effectors that could dampen PTI responses. Thus, the mechanisms utilized by this pathogen to combat PTI have remained obscure. Some bacterial pathogens can evade host recognition by actively altering the composition and/or structure of carbohydrates on the cell surface. We demonstrate that $X$. fastidios $a$ utilizes the prominent $O$ antigen surface carbohydrate to shield PAMPs from early detection by the grapevine innate immune system, thus altering subsequent deployment of defense responses. We identified specific transcriptional and phenotypic responses activated by $\mathrm{O}$ antigen mutant strains during the early stages of infection in grapevine. These results provide unprecedented insight into the molecular mechanisms underlying this hostpathogen interaction.

\section{Regulation of denitrification in R. solanacearum}

A. TRUCHON (1), B. Dalsing (1), C. Allen (1)

(1) University of Wisconsin Madison, U.S.A.

Soil-dwelling plant pathogens need rapid metabolic adaptation to transition between the diverse micro-niches in soil and inside host plants. Tomato xylem is low in oxygen and relatively nutrient-poor, but contains around $30 \mathrm{mM}$ nitrate $\left(\mathrm{NO}_{3}{ }^{-}\right)$. The bacterial wilt pathogen Ralstonia solanacearum exploits these attributes of the xylem environment by using inorganic nitrogen species as terminal electron acceptors to generate ATP via denitrification. We used a series of $R$. solanacearum mutants to show that the NarG - AniA - NorB - NosZ denitrification pathway is needed for virulence, contributes to $\mathrm{NO}_{3}^{-}$respiration, and detoxification of reactive nitrogen species like nitrite $\left(\mathrm{NO}_{2}^{-}\right)$and nitric oxide (NO) validating its important biological role. To explore this key pathway's regulation, I mutated NorA and NorR homologs in $R$. solanacearum. NorA and NorR have been shown to play a role in regulation of the NO reductase NorB in $R$. eutropha. Preliminary results indicate that the $R$. solanacearum $\Delta$ norA, $\Delta n o r R$ and $\Delta n o r A R$ mutants grew poorly aerobically and under denitrifying conditions. The $\triangle n o r A, \Delta n o r R$ and $\triangle n o r A R$ strains were also more susceptible to NO toxicity, accumulated more NO, and exhibited greater oxidase inhibition than wild-type $R$. solanacearum. These results suggest that $R$. solanacearum NorA and NorR may indirectly regulate denitrification by binding NO, and controlling the NO pool. Additionally NorR may directly regulate denitrification at the transcriptional level.

\section{Evolution of plant pathogenicity in Streptomyces}

Y. ZHANG (1), D. Bignell (2), R. Zuo (3), Q. Fan (4), J. Huguet-Tapia (1), Y. Ding (3), R. Loria (1)

(1) Department of Plant Pathology, University of Florida, Gainesville, FL, U.S.A.; (2) Department of Biology, Memorial University of Newfoundland, Canada; (3) Department of Medicinal Chemistry, University of Florida, Gainesville, FL, U.S.A.; (4) College of Plant Protection, Fujian Agriculture and Forestry University, China 
Approximately ten Streptomyces species including the most widely distributed Streptomyces scabiei cause the potato scab disease. The main pathogenicity determinant of scab-causing Streptomyces species is the phytotoxin known as thaxtomin A (ThxA). In S. turgidiscabies, ThxA biosynthetic genes reside on a mobile pathogenicity island (PAI). However, the PAI mobilization in other Streptomyces species remains uncharacterized. We investigated the mobilization of the PAI of S. scabiei 87-22 both in vivo and in vitro. We sequenced genomes of ten pathogenic Streptomyces isolates from different locations, inferred the evolutionary relationships of pathogenic Streptomyces species, and identified a novel pathogenic species (S. sp. 9612) that was isolated from Egypt. The PAI in $S$. sp. 96-12 is identical to the PAI in $S$. scabiei 87-22 despite differences in their whole genome sequences. This strongly suggested in vivo mobilization of this PAI in these two strains. To test whether the PAI in S. scabiei 87-22 could indeed be mobilized, $S$. scabiei 87-22 deletion mutants with antibiotic resistance markers in the PAI, were mated with $S$. diastatochromogenes, a nonpathogenic species. The PAI of S. scabiei was found to be site-specifically inserted into the aviXI gene of S. diastatochromogenes and conferred pathogenicity. Our results demonstrated that the mobilization of the S. scabiei PAI could be responsible for the emergence of novel pathogenic species.

\section{Viruses in nature: Persistent plant viruses}

R. VALVERDE (1)

(1) Louisiana State University Agricultural Center, U.S.A.

In nature, viruses are ubiquitous and play an important role in ecosystems. It has been shown that they are the most common biological entity of fresh and sea water. Plant viruses can be divided into two categories: acute and persistent. Acute viruses cause symptoms in their plant hosts. Most acute viruses cause diseases in economically important crops, and infected plants can be found everywhere crops are grown. In most cases, the effect of acute viruses on the plant phenotype consists of foliar discolorations and tissue malformations. In contrast, persistent viruses do not cause detectable symptoms and have been reported in specific cultivars of many economically important crop species. Most persistent viruses in plants have been detected by electrophoretic analyses of viral dsRNAs or by detection methods based on nucleotide sequencing. Preliminary studies suggest that persistent viruses do not appear to be common in nature. In a survey for persistent viruses in non-cultivated plant species conducted in Louisiana, only 9 of 132 plant species belonging to 60 families were found to contain persistent viruses. Of those viruses detected, six were in the family Endornaviridae. The role that persistent viruses play in the plant host is not known.

Players in the phytobiome: vector-borne viruses and their interactions with insect hosts A. WHITFIELD (1), D. Rotenberg (1)

(1) Kansas State University, U.S.A.

The majority of economically-important plant viruses are transmitted by arthropod vectors. While the ecological interactions among plants, viruses, and vectors are known to be influenced by various abiotic and biotic factors, relatively little is known about the molecular basis of acquisition and transmission of viruses to plant hosts. Our initiative is to catalog and characterize the direct interactions between propagative viruses and their insect hosts. The corn planthopper (Peregrinus maidis) and Maize mosaic virus (MMV, genus Nucleorhabdovirus) system is a tractable framework for studying molecular virus-vector interactions. We use RNA-Seq and yeast two-hybrid assays (Y2H) to describe the vector transcriptome and interactome. Infection of $P$. maidis with MMV resulted in the differential expression of 144 transcripts, and $\mathrm{Y} 2 \mathrm{H}$ analysis of MMV glycoprotein (G) interactions with $P$. maidis revealed more than 100 unique interactors that may play roles in vector competence. A significant number of $P$. maidis transcripts that were responsive to MMV infection (39\%) or interacted with G (59\%) were non-annotated, a finding that underscores the need for resolving gene function in non-model insects in general, and more specifically herbivorous vectors. These findings provide a foundation for future work on functional analysis of molecular determinants of plant virus transmission in the context of complex genetic and environmental factors that shape the phytobiome.

\section{Characterization of diverse virus populations associated with plant-pathogenic nematodes}

S. BEKAL (1), K. Lambert (1), G. Tylka (2), K. Bhalerao (1)

(1) University of Illinois, U.S.A.; (2) Iowa State University, U.S.A.

Viruses have not been used for nematode control because few nematode infecting viruses have been identified. Recently, five viruses were discovered that infect Heterodera glycines, the soybean cyst nematode ( $\mathrm{SCN}$ ). Our objectives were to identify mechanisms of virus transmission, to assess virus prevalence in natural SCN populations and to estimate virus-mediated damage to infected nematodes. Viruses were detected in SCN populations using quantitative reverse transcription PCR. All developmental stages of SCN were tested and found to contain viruses, suggesting that viruses are transmitted vertically or via male SCN during mating. Surprisingly, virus-infected SCN appear to have increased motility as compared to uninfected SCN. While one laboratory culture of SCN contained all known SCN viruses, most field SCN populations harbored only one or two viruses. The frequency of field SCN populations containing viruses varied by location, but viral incidence was up to $100 \%$ at some field sites. By monitoring multiple generations of virusinfected SCN, specific viruses appeared to be suppressed in the nematode generation after the virus titer reached a high level. The reduction of specific virus levels may be due to virus-mediated damage to the eggs, preventing their hatching and lowering the virus titer in the next nematode generation. The observation that nematode viruses may damage SCN eggs suggests that SCN viruses may be exploited as biological control agents of SCN.

\section{Virus-induced changes in grass systems biology}

K. MANDADI (1), K. Scholthof (2)

(1) Texas A\&M AgriLife Research, U.S.A.; (2) Texas A\&M University, U.S.A.

Grass viral diseases cause significant losses to global agricultural production, yet little is known about grass-virus interactions and antiviral defenses, when compared to dicot-virus interactions. To address this knowledge-gap, we established and utilized Brachypodium distachyon and Setaria viridis as models for $\mathrm{C}_{3}$ and $\mathrm{C}_{4}$ grass-virus interactions, respectively. Using tiling microarrays, high-throughput RNA-sequencing, and LC-MS/MS tools, we analyzed the transcriptome-, spliceome-, and metabolite-level changes occurring during Panicum mosaic virus (PMV) infection of Brachypodium. Further, using Brachypodium and Setaria as host plants, and six other monocot-infecting viruses (Brome mosaic virus, Barley stripe mosaic virus, Maize mild mottle virus, Sorghum yellow banding virus, Wheat streak mosaic virus and Foxtail mosaic virus), we dissected conserved, as well as virus-specific, and host-dependent effects in defense hormone responses and alternative splicing processes affected during diverse $\mathrm{C}_{3}$ and $\mathrm{C}_{4}$ grass:virus interactions. Together, these investigations provided new insights in our understanding of grass systems biology and antiviral defenses modulated during agronomically-significant grass virus infections. This knowledge could be useful to develop tools and strategies to mitigate crop losses caused by grass virus infections.

\section{Plant-virus protein interaction and localization maps: Where's the game and who's on the team?} M. Goodin (1)

(1) University of Kentucky, U.S.A.

Viruses pose constant threats to human health and welfare. My laboratory has focused primarily on Potato yellow dwarf virus (PYDV) and Sonchus yellow net virus (SYNV), two members of the genus Nucleorhabdovirus, defining characteristics of which are their replication in nuclei of infected cells and accumulation of mature virions in the perinuclear space after budding through the inner nuclear membrane. More recently, we have investigated the Dichorhavirus ("bipartite rhabdovirus"), coffee ringspot virus, which has emerged in the majority of the coffee producing areas in Brazil. In order to 
characterize these viruses, and with the help of collaborators, we developed several enabling technologies. The first of these, the pGD vectors, are described in a 2002 publication that is currently linked to 98 citations spanning a wide range of plant and microbial research. The subsequent second and third generation pSITE and pSITEII protein expression vectors are linked to 57 and 48 citations, respectively. Most of these vectors have been employed in experiments utilizing the model plant Nicotiana bethamiana, the first comprehensive review of which has been downloaded $>1500$ times from the MPMI website, where it remains the third most accessed publication on that site. Using examples from my own research and of others, the need for vastly expanded protein localization and interaction databases will be discussed.

Summary-The role of viruses in the phytobiome

J. SCHOELZ (1)

(1) University of Missouri, U.S.A.

Plant viruses have the capacity to modulate the response of their hosts to biotic and abiotic stresses. Plant viruses have been shown to alter host physiology, increasing tolerance to drought stress and inducing or repressing defenses against bacterial and fungal pathogens. In addition, plant viruses can induce subtle changes in their hosts that affect vector performance or preference. What is intriguing about these changes in host physiology is that they are initiated by a pathogen with a very small genome size, as many plant virus genomes are smaller than $10 \mathrm{~kb}$ and may encode as few as three proteins. Plant viruses may induce alterations in their hosts through production of small RNAs or through protein-protein interactions. Recent studies have shown that individual virus proteins likely interact with multiple targets in the host to facilitate infection and/or to modulate plant defenses. For example, the P6 effector of Cauliflower mosaic virus interacts with at least 14 host and virus proteins to influence such diverse functions as translation of virus proteins, intracellular movement of virions, gene silencing, plant defenses, and symptom development. This presentation will focus on how the development of interactome maps composed of both virus and host proteins may shed light on the influence viruses have on specific functions in their hosts.

\section{Use of sequencing technologies in controlling downy mildew of lima bean}

T. MHORA (1)

(1) University of Delaware, U.S.A.

Lima bean is an important crop for Delaware and is affected by severe downy mildew epidemics caused by the oomycete Phytophthora phaseoli. Implementing integrated pest management (IPM) strategies could result in yield increases, reduced production costs and environmental benefits. Of the six documented races of $P$. phaseoli $(\mathrm{A}-\mathrm{F})$, race $\mathrm{F}$ is currently predominant in the mid-Atlantic region creating a need for downy mildew resistant lima bean cultivars. Molecular markers (Kompetitive Allele Specific PCR assays) for detecting race F resistance in lima bean were developed using bulked segregant analysis via genotyping-by-sequencing (GBS). These assays accurately predicted race F resistance in a collection of 256 genetically diverse lima bean accessions (diversity panel). In order to implement resistance gene pyramiding as part of our IPM strategy, the diversity panel is being used to discover different sources of downy mildew resistance. Lima bean lacks a reference genome complicating analysis of GBS data from diverse accessions. To characterize the genetic diversity of the panel using GBS, data from a biparental maize population was used to develop filters and to better understan how data is handled in our custom non-reference bioinformatics pipeline compared to a reference based analysis. Optimized analysis of GBS data from the diversity panel together with disease resistance phenotype data will allow the identification of important loci for downy mildew resistance.

\section{Comparative genomics of downy mildews}

R. MICHELMORE (1), C. Tsuchida (2), J. Gill (3), K. Wood (3), L. Derevnina (3), S. Reyes Chin Wo (3), K. Fletcher (3)

(1) UC Davis, U.S.A.; (2) UC Davjs, U.S.A.; (3) UC Davis, U.S.A.

Downy mildews (DMs) cause diseases on a wide range of plants. Individual species have narrow host ranges and exhibit high degrees of host specialization. We utilized high throughput sequencing to generate de novo genome assemblies of geographically and temporally separated isolates of Bremia lactucae (lettuce DM), Peronospora effusa (spinach DM), P. schachtii (chard DM), P. tabacina (tobacco DM), Peronosclerospora sorghi (sorghum \& maize DM), and Sclerospora graminicola (pearl millet DM) in collaboration with experts for each pathogens. These genome assemblies were highly syntenic but varied greatly in size $(50-\sim 320 \mathrm{Mb})$, gene content $(12-20 \mathrm{~K})$, repeat content $(15-\sim 60 \%)$, and repertoire of genes encoding effectors and other pathogenicity-related proteins. No families of RXLR-containing effectors are common across all DMs; however, RXLR families overlap greatly between isolates within species. DM is the most important disease of lettuce in California and worldwide; B. lactucae is highly variable and can rapidly change to overcome resistant cultivars. We have monitored changes in virulence phenotypes of B. lactucae in California since 1982 . Appearance of the $\mathrm{B}_{1}$ mating type may explain the recent increase in novel virulence phenotypes and may require a change in strategy for resistance gene deployment. Genomic sequence analysis of representative isolates collected in California and Europe over three decades provides detailed information of variation of $B$. lactucae.

Application of metagenomics for virus disease management in perennial crops: A Case Study of Grapevine red blotch disease in North America M. SUDARSHANA (1)

(1) USDA ARS, Davis, CA, U.S.A.

Genomics in plant virology began with deciphering the genome of Tobacco mosaic virus in 1982. Since then, functional genomics of virus-encoded proteins has been examined beginning with the demonstration of coat protein-mediated resistance in transgenic plants and infectious clones of plant viruses. While close to 1,200 plant viruses have been recognized as of 2014, new viruses continue to be added to this list largely by metagenomic analysis of the RNA pool in symptomatic plants by deep sequencing. Primarily, double-stranded RNA, small RNA and total RNA fractions have been used to make cDNA libraries to find new viruses and/or variants of known plant viruses. This is especially important in understanding the etiology of diseases suspected to be caused by viruses and also to recognize latent virus infections in perennial crop plants such as grapevines, fruit and nut trees. The discovery of Grapevine red blotch-associated virus and recognition of grapevine red blotch as a disease of importance in wine grape production in North America illustrates the power of metagenomics in the diagnosis and management of diseases caused by viruses.

Genomics of bacterial pathogen populations as a tool to inform crop disease prevention and control

B. Vinatzer (1)

(1) Virgina Tech, VA, USA

Next Generation genome sequencing has already transformed how we study the biology of plant pathogenic bacteria and their interaction with host plants. Moreover, while just a few years ago we sequenced the genomes of a few strains representative of a pathogen, we can now easily sequence every single outbreak strain of a pathogen. This allows us to investigate the genetic diversity of an entire pathogen population instead of analyzing the genome of a single strain. Using Pseudomonas syringae and Ralstonia solanacearum as examples, we show the new insights we have gained into disease emergence, pathogen dissemination, evolutionary histories, and virulence mechanisms of these pathogens and how these insights can inform disease prevention and control. Finally, we will show how a genome sequence-based taxonomy can provide precise names for bacterial taxa at almost any level of diversity, from a bacterial family to a single outbreak strain. We expect this precise taxonomic system to aid in pathogen identification and disease diagnostics and, consequently, allow for targeted disease control. 
Integrating GBS, RNA-Seq, and AmpSeq data for analysis of powdery mildew resistance in grapevine

L. CADLE-DAVIDSON (1)

(1) USDA ARS, Geneva, NY, U.S.A.

No Abstract Available

Activity and repurposing of native CRISPR-CAS systems

R. BARRANGOU (1)

(1) NC State University, U.S.A.

Clustered regularly interspaced short palindromic repeats (CRISPR) and CRISPR-associated proteins collectively constitute a DNA-encoded, RNAguided, nucleic acid-targeting adaptive immune system. Although a plethora of diverse CRISPR-Cas systems are widespread in many bacterial phyla, only a few model systems have been characterized to date. Here, we investigate the occurrence and diversity of CRISPR-Cas systems in lactobacilli and characterize their activity in native hosts. Specifically, we show that endogenous Type II systems are natively active in several Lactobacillus species and provide interference against the uptake of plasmids that carry sequences matching recently acquired spacers. We also characterize a diversity of CRISPR transcripts (crRNAs, tracrRNAs) and PAMs, and show a diversity of guide sequences and structures. Noteworthy, diverse PAMs with varying GC content provide flexibility for targeting of nucleic acid sequences in genome editing applications. We also show that some of these systems can be repurposed as potent antimicrobials by providing self-targeting guides that co-opt the natural CRISPR machinery. Furthermore, we illustrate how selftargeting can also be used as a screening method to identify essential genes and genomic regions. Collectively, these results open new avenues for applications of Type II CRISPR-Cas systems and highlight the need to investigate and characterize CRISPR-Cas systems in native hosts.

\title{
CRISPR RNA-guided Genome Editing in Human Stem Cells, Animals, and Plants
}

J. KIM (1)

(1) Center for Genome Engineering, Institute for Basic Science, South Korea

Genome editing that allows targeted mutagenesis in higher eukaryotic cells and organisms is broadly useful in biology, biotechnology, and medicine. We have developed ZFNs, TALENs, and Cas9 RNA-guided endonucleases (RGENs), derived from the type II CRISPR-Cas prokaryotic adaptive immune system, to modify chromosomal DNA in a targeted manner. In particular, we used purified Cas 9 protein and in vitro transcribed guide RNAs rather than plasmids encoding these components to correct large chromosomal inversions in the blood coagulation factor VIII gene that cause hemophilia A in patient-derived induced pluripotent stem cells (iPSCs) and to modify diverse genes in large animals and plants. The resulting animals and plants contained small insertions or deletions (indels) at target sites, which are indistinguishable from naturally-occurring variations, possibly bypassing regulatory requirements associated with use of recombinant DNA. Despite broad interest in RNA-guided genome editing, RGENs are limited by offtarget mutations. We developed Cas9 nuclease-digested whole genome (digenome) sequencing (Digenome-seq) to profile genome-wide specificities of Cas9 nucleases in an unbiased manner. Digenome-seq captured nuclease cleavage sites at single nucleotide resolution and identified off-target sites at which indels were induced with frequencies below $0.1 \%$.

\section{CRISPR/dCas9 technologies for transcriptome manipulation and disease research}

S. QI (1)

(1) Stanford University, U.S.A.

The bacterial CRISPR/Cas9 system offers a powerful approach for sequence-specific genome engineering in diverse organisms. In addition to genome editing, we have developed the nuclease-dead dCas9 technology and methods for temporal and multi-gene regulation. We recently created a general orthogonal dCas9-based platform to enable parallel transcriptome manipulation. We further applied the technologies to address the needs for genetic disease modeling using human stem cells and the non-editing based approaches for therapeutic applications.

\author{
Development of citrus canker resistant varieties by manipulation of $C S L O B 1$, the citrus susceptibility gene to Xanthomonas citri, using \\ Cas9/sgRNA \\ N. WANG (1), H. Jia (1) \\ (1) University of Florida, U.S.A.
}

Citrus canker caused by Xanthomonas citri subspecies citri $(\mathrm{Xcc})$ is a severe disease for most commercial citrus cultivars. Generating canker resistant citrus varieties will provide an efficient and sustainable solution to control citrus canker. PthA4 is the dominant pathogenicity gene of Xcc and recognizes the corresponding promoter sequence in the host and activates the expression of susceptibility gene CsLOB1. Here, we report our latest progress in generating canker resistant citrus by modifying the CsLOB1 gene and the effector binding elements (EBEs) of PthA4 in the CsLOB1

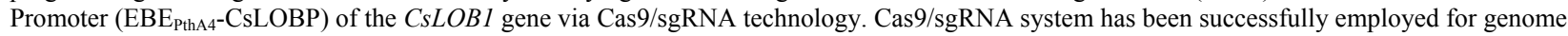
modification in multiple plant species. We have successfully mutated the EBEs of one allele (Type I), but not the second allele (Type II) in Duncan grapefruit. The mutated Duncan grapefruit is susceptible to wild type Xcc, but resistant to Xcc $\Delta$ pthA4:dCsLOB1.3, a pthA4 mutant of Xcc expressing an artificially designed dTALE dCsLOB1.3, which specifically recognizes Type I CsLOBP, but not mutated Type I CsLOBP and Type II CsLOBP. Our data suggest that activation of a single allele of susceptibility gene CsLOB1 by PthA4 is enough to induce citrus canker disease and mutation of the promoters of both alleles of $C S L O B 1$ is required to generate citrus canker resistant plants. We will also present our progress in generating canker resistant citrus by modifying CsLOB1.

Revenge of the phage: Anti-CRISPRs strike back

J. BONDY-DENOMY (1)

(1) University of California, San Francisco, U.S.A.

Bacteria face a constant threat of being infected and killed by viruses called phages. In response, bacteria have developed an adaptive immune system called CRISPR-Cas, which protects cells from phage infection and has recently been repurposed into a revolutionary gene-editing tool. Phages infecting Pseudomonas aeruginosa, however, have evolved a mechanism to interfere with CRISPR-Cas function by producing proteins called "anti-CRISPRs". We have identified many different anti-CRISPR proteins that are completely distinct from each other and inhibit CRISPR-Cas function through diverse mechanisms. One anti-CRISPR binds to the nuclease protein and inhibits its recruitment, while other anti-CRISPRs bind to the CRISPR-Cas surveillance complex and prevent it from binding to a DNA target. Further, anti-CRISPR proteins have quantifiably different efficiencies, based on whether they target the first step (i.e. DNA binding) or second step (i.e. nuclease recruitment) of CRISPR-Cas function. Anti-CRISPRs that target the first step face a kinetic challenge in battling with CRISPR and are thus inefficient, while an efficient anti-CRISPR targets the second step, but can be driven to inefficiency by upregulating CRISPR-Cas targeting. By studying the outcome of anti-CRISPR - CRISPR interactions, we hope to gain new insight into CRISPR-Cas function and enhance our understanding the natural ecological battle between bacteria and their viruses.

Balancing a Successful Career and Family

J. CRANE (1), F. Baysal-Gurel (2), M. Brewer (3)

(1) Valent BioSciences Corporation, U.S.A.; (2) Tennessee State University, U.S.A.; (3) University of Georgia, U.S.A. 
Whether you are a student, postdoc, or established researcher, balancing work and family life can be a challenge, but as many successful scientists with families can attest, it can be done. You do not have to opt out of a science career to raise a family or give up family life to be a successful plant pathologist. Experiences and advice on managing family and career responsibilities will be discussed at four roundtables, and participants are invited to rotate tables every 15 minutes. Topic areas to be discussed will be balancing a successful career and family life when: 1 . You are a dual career couple or a single parent/single caregiver (moderated by Lance and Molly Cadle-Davidson and Francesca Hand); 2. You have children and/or are a caregiver of an adult family member (moderated by Timothy Murray); 3 . You or one of your family members are dealing with temporary or ongoing health or medical issues, including special needs (moderated by Amy Charkowski); 4. You know your rights under the Family and Medical Leave Act, including leave for maternity/paternity, adoption, and caregiving (moderated by Carla Garzon and Samantha Thomas). Strategies for coordinating work and home life vary from person to person, but balancing the two can be very satisfying on both professional and personal levels.

\section{Management of Aspergillus and Fusarium ear rot diseases}

K. WISE (1), T. Isakeit (2), R. Heineger (3), C. Woloshuk (4)

(1) Purdue University, U.S.A.; (2) Texas A\&M University, U.S.A.; (3) North Carolina State University, U.S.A.; (4) Purdue University, U.S.A.

Aspergillus and Fusarium ear rots of maize are chronic diseases in the southern United States and are periodically important in the Mid-South and Midwestern U.S. The fungi that cause these diseases produce mycotoxins that are harmful to both humans and animals. Research trials were conducted from 2013 to 2015 in Indiana, North Carolina and Texas to evaluate the efficacy of several rates of commercially-available atoxigenic products for control of Aspergillus and Fusarium ear rots, determine the value of insect-resistant (Bt) hybrids for mycotoxin control, and efficacy of foliar fungicide applications for ear rot and mycotoxin control. Fungicides did not reduce ear rots or mycotoxins in any state or year. Insect-resistant hybrids did reduce mycotoxin levels in Texas and Indiana in several years, but not in North Carolina. Atoxigenic product efficacy varied, and economic gains from using this management strategy occurred when mycotoxin contamination was high. Our research indicates that regional environmental and crop production differences influence efficacy of management practices for mycotoxins, and additional research is needed to determine region-specific management practices of these ear rots.

Identifying new genetic targets for maize ear rot and mycotoxin control through computational subnetwork module analyses W. SHIM (1), M. Kim (1), H. Zhang (1), H. Yan (1), B. Yoon (1), G. Payne (2), C. Woloshuk (3)

(1) Texas A\&M University, U.S.A.; (2) North Carolina State University, U.S.A.; (3) Purdue University, U.S.A.

Fumonisins and aflatoxins are two most important mycotoxins in corn with significant risk on market value and health. Tools and strategies currently available to manage mycotoxins are not consistently effective, and there is a need to develop reliable preharvest control strategies, e.g. biocontrol agents and transgenic hybrids, to minimize the entry of mycotoxins into our food supply. With this aim we began screening for new genetic targets for disrupting fungal pathogenicity. We performed Fusarium verticillioides and Aspergillus flavus RNA-Seq from multiple kernel samples (from different maize lines and conditions) and developed a systematic computational network analysis pipeline to discover pathogenicity subnetwork modules. We first built the co-expression networks of these fungi, and subsequently identified functional subnetwork modules consisting of genes that display strongly coordinated behavior in the respective datasets. A computationally efficient branch-out technique, with a probabilistic pathway activity inference scheme, was used to identify functional subnetwork modules likely involved in ear rot and mycotoxin production. These modules contain several enriched GO terms as well as potential pathogenicity genes. Subsequently, we selected putative hub genes in each subnetwork and performed molecular characterization to test their candidacy as new targets for ear rot and mycotoxin control strategies.

Accelerating the selection of candidate genes to control mycotoxin contamination of maize through host-induced gene silencing (HIGS) B. BLUHM (1), J. Smith (2), Y. Ramegowda (2), B. Dhillon (2), W. Shim (3), C. Woloshuk (4)

(1) University of Arkansas, U.S.A.; (2) University of Arkansas, U.S.A.; (3) Texas A\&M University, U.S.A.; (4) Purdue University, U.S.A.

The maize ear rot pathogens Fusarium verticillioides and Aspergillus flavus contaminate grain with fumonisins and aflatoxins, respectively. Both categories of toxins pose severe health risks and limit grain marketability. Despite extensive breeding efforts in maize, adequate resistance to mycotoxin accumulation has not been developed. Additionally, current tools available to control mycotoxin contamination in maize are limited in number and efficacy. Recently, host-induced gene silencing (HIGS) utilizing hairpin RNA (hpRNA) has been advanced as an approach to silence genes underlying plant pathogenesis in filamentous fungi. We developed an efficient process to select and evaluate fungal gene targets for HIGS. In this approach, hpRNA constructs are evaluated for their ability to suppress target gene expression in fungi before transgenic maize plants are created. Our strategy to create hpRNA constructs minimizes cloning steps, thus accelerating the evaluation of candidate genes and creation of transgenic maize plants. To date, constructs have been created that target fumonisin and aflatoxin biosynthetic genes, as well as global regulators of mycotoxin biosynthesis. Advanced lines of transgenic maize plants are currently being tested for suppression of mycotoxin biosynthesis.

\section{Developing the next generation of biological control: Genomic approaches for predicting most effective stains} I. CARBONE (1), M. Sexton (1), R. Gell (1), J. White (1), R. Singh (1), T. Isakeit (2), B. Bluhm (3), K. Wise (4), C. Woloshuk (4), B. Horn (5), R. Heiniger (6)

(1) Center for Integrated Fungal Research, Department of Plant Pathology, North Carolina State University, Raleigh, NC, U.S.A.; (2) Department of Plant Pathology and Microbiology, Texas A\&M University, College Station, TX, U.S.A.; (3) Department of Plant Pathology, University of Arkansas, Fayetteville, AR, U.S.A.; (4) Department of Plant Pathology and Botany, Purdue University, West Lafayette, IN, U.S.A.; (5) United States Department of Agriculture, Agricultural Research Service, Dawson, GA, U.S.A.; (6) Department of Crop Science, North Carolina State University, Raleigh, NC, U.S.A.

Biological control using atoxigenic Aspergillus flavus strains is an effective method for reducing preharvest contamination of maize and other crops with aflatoxins. Despite their efficacy, biocontrol strains do not persist and must be reapplied at high rates annually for sustainable aflatoxin mitigation. The genetic, environmental and ecological factors that impact biocontrol strains once introduced into fields is not understood, nor are the long term successional changes on population genetic structure that may impact the efficacy of introduced strains. To gain a better understanding of shifts in population structure, we sampled A. flavus from soil and kernels prior and subsequent to treatment with biocontrol strains in cornfields in North Carolina, Indiana, Arkansas and Texas. Genome wide polymorphisms derived from targeted genome sequencing were used to track fluctuations in the chromosomal and mitochondrial genetic backgrounds of introduced and native A. flavus strains. Comparative genomics and phylogenetics revealed native strains sharing common genetic backgrounds with biocontrol strains, but also regional differences that could be lineage specific. For each state, four native strains of complementary mating type, mitochondrial haplotype and nuclear background were selected and deployed as biocontrols in 2015. A. flavus will be sampled to test hypotheses of introgression, shifts in sexual fertility, and heritability of atoxigenicity over several generations.

\section{Tapping into growers' expertise: Effective engagement in extension} L. DU TOIT (1)

(1) Washington State University, Mount Vernon, WA, U.S.A.

Developing an effective plant pathology extension program that is synergistic with your research and teaching responsibilities necessitates developing methods of integrating the expertise of growers and other stakeholders into your program. Developing efficient two-way communication is essential to convey plant pathology expertise to growers and, more importantly, to develop an understanding of growers' priorities and perceptions in relation to 
plant diseases and disease management. Active listening facilitates your understanding of how growers' practices might influence plant diseases, and identifies potential constraints to developing and integrating disease management practices into their farming systems; it also contributes to new research ideas with greater probability of being translated into real impacts for growers. Engaging in formal (e.g., field days, meetings, workshops, surveys, grower-cooperator trials, websites, publications) and informal (e.g., over coffee, in small groups, field visits) communication helps you connect with the diversity of personalities and types of growers, thereby strengthening your extension efforts. Intentionally seeking grower input when designing applied research projects leads to a vested interest of growers in the research, informs growers of research methods and standards, demonstrates the strength of your engagement, contradicts the stereotype of 'ivory-tower academics', and contributes to the U.S. Land Grant mission.

\section{Have I told you about the time...: Communicating "Plant Pathology" to diverse audiences in academia}

J. BRADEEN (1), D. VanBoxtel (2)

(1) University of Minnesota, U.S.A.; (2) University of Minnesota, U.S.A.

Communicating the essence, relevance, and impact of "plant pathology" within our academic institutions requires (1) consistency and clarity of message, (2) flexibility in aligning our message with the diverse and sometimes conflicting interests of students, faculty, college and university administrators, and alumni and donors and (3) creativity in message delivery. At the University of Minnesota, promoting the Department of Plant Pathology has been a significant priority in recent years. Our goals include helping students discover plant pathology as a potential career path, raising functional understanding of our science among college administrators, promoting the impact of our Department at the college and university level, and keeping alumni and friends informed about the great work of our students, staff, and faculty. In this presentation, we will explore some of the challenges and successes we've had in defining and implementing a communications and marketing strategy for the Department. We will discuss how each audience requires a different strategy and different delivery mechanism(s). We will also explore the potential of applying analytical approaches to inform and refine communications strategy.

Think local, act globally: Meeting stakeholders' needs in developing countries

A. TESTEN (1), S. Miller (1)

(1) The Ohio State University, U.S.A.

Resource-poor farmers in developing countries are especially affected by the economic and environmental consequences of plant diseases. Plant pathologists can mitigate these impacts through research to develop locally appropriate solutions and effective outreach to enhance their diffusion. A multidisciplinary, participatory approach was used to develop a program to improve soil and plant health on smallholder tomato farms in the Morogoro Region of Tanzania. Farmers' local knowledge of plant diseases and soils was gathered to improve communication between farmers and researchers. This local knowledge helped to identify key regional tomato diseases and soil constraints. We also engaged farmers in a type of participatory evaluation of local and introduced tomato germplasm called mother-baby trials, which places farmers at the center of the selection process and enhances dissemination of new varieties. Farmers were also trained on use of a low-cost soil health test kit, which allowed them to assess soil health in their own fields. These participatory approaches engage farmers at all stages of research and can enhance farmers' acceptance and dissemination of introduced technologies.

Pulling no punches: Admitting you don't know, and still giving actionable answers

W. MAHAFFEE (1)

(1) USDA ARS, Corvallis, OR, U.S.A.

The difference in perspective between growers and researchers often creates a communication gap that must be filled in order for both groups to succeed. When growers ask researchers a question they often get a nuanced answer that can be noncommittal and perceived as uninformative by growers. This is because researchers are often hesitant to make recommendations based on guesses or too many assumptions. However, growers are usually asking questions because they have no choice but to make a decision - usually right then. They do not want a nuanced answer but they do want to understand the uncertainty and logic in the educated guess that you might have to give. There are also interactions where researchers are frustrated by the lack of grower implementation of their or others research. Here again is a communication gap that is often related to inefficient communication. Growers often recognize that the research could be helpful but do not see how they can change their production system to utilize it because of logistics or labor or equipment availability. Both groups often think that the other does not under their system. Getting both parties to adapt to and see the others perspective usually results in improved research support and implementation.

\section{The business of working with stakeholders}

W. Dolezal (1)

(1) DuPont Pioneer, U.S.A.

Identifying your stakeholders and understanding their specific needs are important components for running a successful business. The goal is to provide useful information in a timely manner for achieving improved product performance, improving workload efficiency and hopefully improving profitability for both the stakeholder and the company. Internal stakeholders include your team members and administrators, your company colleagues in sales, production/manufacturing and research. External industry stakeholders are many, including farmers/growers; intermediate or end users of your product; local, state, federal or international governments; professional and trade organizations and the communities where you conduct business. Building a reputation for being knowledgeable, honest, accurate and timely in providing useful information that benefit stakeholders is a major key to business grow \& sustainability. It is also key for building a successful career.

Rose rosette disease: History, symptoms, and viral pathogen

I. TZANETAKIS (1), P. Di Bello (2), T. Druciarek (3)

(1) Plant Pathology, University of Arkansas, U.S.A.; (2) Oregon State University, U.S.A.; (3) University of Arkansas, U.S.A.

Rose rosette was first described in the 1940s and has since been the most important virus disease in North America causing plant death in few years after infection. The disease is caused by the homonymous virus, a member of the eriophyid mite-transmitted genus Emaravirus which includes multipartite negative sense RNA viruses forming unique double-bound membrane particle. Rose rosette virus (RRV) is transmitted by Phyllocoptes fructiphilus (Keifer) with an acquisition access period of five days and inoculation access period of less than one hour. In contrast to anecdotal accounts, the virus can move systemically in the plant and survive between seasons. Similar to other negative strand RNA plant viruses RRV appears to replicate in its vector. Because of the difficulty controlling eriophyid mites genetic resistance appears the better control strategy. Several genotypes have been screened for resistance to the mite and the virus. Where none was found resistant to the vector, a sole genotype, 'Stormy Weather ${ }^{\mathrm{TM}}$, proved resistant to the virus in both grafting and vector transmission experiments. The implications of the recent findings in disease and vector control will be discussed.

Development of efficient diagnostic tools to enable rapid, easy-to-use, accurate and affordable detection of Rose rosette virus F. OCHOA-CORONA (1), A. A.M. Salazar Aguirre (2), S. Molina Cárdenas (2), A. Olmedo-Velarde (2), S. Dobhal (3), J. Olson (1), B. Babu (4), M. Paret (4)

(1) Oklahoma State University, Stillwater, OK, U.S.A.; (2) Universidad de las Fuerzas Armadas ESPE, Sangolqui, Ecuador; (3) Kansas State University, Manhattan, KS, U.S.A.; (4) University of Florida, Quincy, FL, U.S.A. 
Rose rosette virus (RRV, Emaravirus) is a major threat to the rose industry and early detection and selective eradication of plants are the only alternative available for disease management. Molecular-based assays with potential for technology transfer and/or on site implementation should be easy to use, offering visual detection, reliability and sensitivity to the end user. Loop mediated isothermal amplification (LAMP) and thermophilic helicase dependent amplification (tHDA) are isothermal DNA amplifications that combines some of these criteria and not requiring thermocycler. Primer design criteria for both LAMP and tHDA with self-quenched primers $(\mathrm{SqP})$ were investigated. A rapid 15 min probe based isothermal reverse transcription-recombinase polymerase amplification (RT-exoRPA) assay was developed. Broad detection of Emaravirus and species discrimination was targeted with Reverse Transcription polymerase chain reaction (RT-PCR) coupled to High Resolution Melting (HRM) analysis. Also a single primer-set suitable for use with three different chemistries: Endpoint RT-PCR, TaqMan-quantitative RT-PCR (RT-qPCR) and SYBR Green RT-qPCR with High Resolution Melting was developed including a clonable synthetic, non-infectious multi-target artificial positive control containing a specific RRV probing site and other five sites for viruses commonly infecting ornamentals. The contribution of these methods within a holistic perspective of RRV diagnostics is presented.

Current state of knowledge on mite transmission and control

R. Ochoa (1), G. Otero-Colina (2), J. Hammond (3), R. Jordan (3), G. Bauchan (1)

(1) USDA, ARS, U.S.A.; (2) Colegio de Postgraduados, Mexico; (3) USDA, ARS, US National Arboretum, U.S.A.

Studies of the eriophyid mite Phyllocoptes fructiphilus which carries the rose rosette virus are being conducted at the microscopic level. Microscope techniques include bright field, DIC, variable pressure SEM and low temperature SEM. The eriophyid mite was first described by Keifer in 1940 but it was first suggested as the vector of RRD by the same author in 1966. The mites were originally collected from fruits around the seeds and the petiole bases of Rosa californica in Clarksburg, California.Today the mite is widely distributed in the U.S. on wild (Rosa multiflora) and commercial roses with different levels of virus damage and its presence is directly affecting rose production and gardening areas. Current studies on roses from different states indicate the presence of several species of eriophyid mites during different seasons of the year on different parts of the rose plants. Mites are primarily found on enclosed petioles/scales of vegetative buds, inside the flower sepals oppressed to the ovary/seeds, and on open leaves during the growing season. Mites appear to be hiding amongst dense simple and bulbous, glandular hairs (trichomes). These mites also overwinter in these same locations. In addition, we found predator mites in the families Phytoseiidae, Tydeidae and Bdellidae associated with these mites which can be used as a biological control. Control of rose rosette should include the removal of all mature fruits and infected plant tissue.

\section{Monitoring and management of Rose rosette disease: Volunteer engagement \\ K. ONG (1) \\ (1) Dept Plant Pathology \& Microbiology, Texas A\&M AgriLife Extension Service, U.S.A.}

Rose rosette disease (RRD) was described on the North American continent in the early 1940s. The causal agent, Rose Rosette Virus, was described in 2011. Current information notes that all roses are susceptible to this disease yet there are indications that some appear to be more tolerant than others. A lack of understanding of the pathogen, vector and the disease has lead to conflicting recommended management methods. In this project, volunteers are utilized to help monitor the extent of the disease, to gain a better understanding of the geographic range of the disease, which cultivars it is able to infect, and also to help spread scientifically sound information regarding this disease and the pathogen that causes it. Various strategies are used to engage volunteers such as educational trainings and workshops, factsheets and posters to help volunteers to recognize suspicious symptoms of this disease. A mobile device app is developed to allow volunteers to report suspected finds captures location and cultivar data, that will be verified by an expert. A key element to volunteer recruitment, engagement and retention is their realization that their contributions are critical to improve management practices for RRD and to the development of RRD resistant plants. The information gain from this project hopes to result in better understanding of RRD and more robust management recommendation.

Identification of sources of resistance and development of hybridization and genetic tools to move resistance into commercial cultivars D. BYRNE (1), P. Klein (2), M. Yan (2), E. Roundey (2), J. Lau (2)

(1) Dept of Horticultural Sciences, Texas A\&M University, U.S.A.; (2) Horticultural Sciences, Texas A\&M University, U.S.A.

Rose Rosette Disease is caused by the Rose Rosette Virus (RRV) and transmitted by a wind-blown eriophyid mite (Phyllocoptes fructiphilus). Little is known about the resistance of the rose to the virus or the mite vector. At present only a few species such as Rosa palustris andRosa setigera but no cultivated roses have been reported resistant to the disease. Preliminary observations of 400 roses indicates that there is resistance to the disease among the cultivated rose germplasm. Experiments in Tennessee and Delaware are in place to verify which cultivars are resistant. Although work is being done with the resistant species, the introgression process of transferring the resistance from a cultivated rose to develop new resistant rose types would be quicker than starting with resistance from a species rose. In both situations, breeding tools such as marker-RRD resistance associations are being explored. The protocol to generate molecular markers via genotyping by sequencing has been developed for roses and a consensus map with more than 1,000 markers has been constructed. Crosses have been made among various RRD resistant rose species and putatively resistant commercial roses on both the diploid and tetraploid level. These populations will allow an accurate assessment of the inheritance of and the identification of markers associated with RRD resistance to accelerate its introgression into a range of rose germplasm.

How bacterial pathogens hijack cellular processes to turn plants into 'Zombies'

S. HOGENHOUT (1), P. Pecher (1)

(1) John Innes Centre, United Kingdom

Phytoplasmas are bacterial parasites of plants that interfere with fundamental developmental processes turning their hosts into 'Zombies'. The 'Zombie' plants look dramatically different from their uninfected peers, displaying for example witches' brooms and leafy flowers. Moreover, these plants become attractive to insect vectors, which distribute the parasites to other plants, which then also become 'Zombies'. We have previously shown that virulence proteins SAP11 and SAP54 of aster yellows witches broom phytoplasma (AYWB) induce witches' brooms and leafy flowers, respectively. SAP11 and SAP54 act by destabilising specific TCP and MADS-box transcription factors. A SAP11 homolog was identified in maize bushy stunt phytoplasma (MBSP), a maize specialist. We found that SAP11_AYWB destabilises all plant class II TCP transcription factors and SAP11_MBSP only a few TCPs. SAP11_MBSP transgenic Arabidopsis and maize plants show witch's broom phenotypes resembling brc1xbrc2 Arabidopsis and tb1 maize mutants. Thus, SAP11 effectors have evolved to target specific TCPs in their host plants.

The impact of Time of Infection on Zebra Chip Symptom Development

C. RUSH (1), F. Workneh (1), L. Paetzold (1), A. Rashed (2)

(1) Texas A\&M AgriLife Research, U.S.A.; (2) University of Idaho, U.S.A.

Zebra Chip (ZC) is an important disease impacting potato production in the Central and Western US. The disease is caused by the bacterium 'Candidatus Liberibacter solanacearum' (Lso), which is transmitted by the potato psyllid. Symptoms of ZC typically don't appear until after flowering and this raised questions of when vector management should be initiated and how long it should continue. A field study was conducted in which plants were infested with bacteriliferous psyllids beginning one week after plant emergence and continuing until a week before harvest. Each week, infested plants were observed and initiation of symptoms and subsequent disease severity were recorded. At harvest, tubers were dug, rated for disease severity, tested for Lso and placed into cold storage. Later they were planted and emergence was recorded. With all infestation dates, it took approximately 23 days for first symptoms to appear and plants infested during the first five weeks after emergence exhibited the worst foliar and tuber symptoms. Plants infested three 
weeks before harvest typically showed no/few foliar symptoms but tuber symptoms were present and Lso detectable. Two weeks before harvest there were no foliar or tuber symptoms but Lso could be detected in a low percentage of tubers. Lso was not detected in tubers infested one week before harvest but a high percentage of these failed to grow after planting. The significance of late season infestations will be discussed.

Genomic insights into citrus greening and its transmission

D. GABRIEL (1), M. Jain (1), L. Fleites (1)

(1) University of Florida, U.S.A.

Ca. Liberibacter asiaticus (Las) systemically infects Asian citrus psyllids without causing evident disease and is transmitted to citrus phloem, causing the severe disease Huanglongbing (HLB) after a surprisingly long incubation period. Las appears to be well adapted as one of several psyllid endosymbionts, but poorly adapted to citrus. Most Las strains described carry bacteriophage, and several phage genes have been identified as likely horizontally transferred lysogenic conversion factors, including a peroxidase, which suppresses a key citrus defense response. Several Las lytic phage late genes, including a functional holin, are activated in planta, but not in infected psyllids. The Las holin promoter was strongly active in driving a GUS reporter in L. crescens (Lcr), a culturable proxy for Las. Activity of the reporter in Lcr was suppressed by aqueous extracts from Las-free psyllids applied outside of the Lcr cells, indicating cell penetration and also partly explaining why Las has not been cultured to date. The suppressor activity was sensitive to heat and proteinase treatment and a repressor-like protein from the psyllid extracts was found to bind the holin promoter. This protein was identified by LCMS/MS as a predicted secreted protein from Wolbachia, a common insect endosymbiont. The in vitro translated Wolbachia protein also penetrated Lcr cells and repressed the GUS reporter, indicating protein-mediated cross-species bacterial gene regulation.

The impact of 'Candidatus Liberibacter solanacearum' and its insect vector on potato production in New Zealand A. PITMAN (1), J. Dohmen-Vereijssen (2), N. Agnew (2), P. Wright (2), F. Shah (2), S. Thompson (2)

(1) The New Zealand Institute for Plant \& Food Research, New Zealand; (2) The New Zealand Institute for Plant \& Food Research, New Zealand

The bacterium 'Candidatus Liberibacter solanacearum' ( $c$ Lso) is vectored by Bactericera cockerelli, commonly known as the Tomato potato psyllid (TPP). The resulting Zebra Chip complex, which recently emerged on potato in New Zealand, is associated with both reduced crop yield and loss of quality. The interaction between insect and bacterium is intricate, however, producing highly variable symptoms in the paddock that make management decisions difficult. Here, we present our data from field and glasshouse trials in New Zealand, which were established to dissect how TPP, $c$ Lso and their interaction can affect the production of seed, table and processing potato crops. In particular, we will discuss the impact of seed tuber-borne inoculum of $c$ Lso and how the presence or otherwise of this bacterium in insect populations may influence the severity of disease observed in the field, depending on the timing of infection. Our results will be discussed in relation to the implementation of seed certification as well as Zebra Chip management programmes in New Zealand and overseas.

Reducing Hemipteran Vectors and pathogen spread, Topically applied RNAi

W. HUNTER (1), E. Andrade (2)

(1) USDA-ARS, U.S.A.; (2) EMBRAPA, Cassava \& Fruits, Brazil

Topically applied, non-transgenic method for RNAi in plants provides a highly specific mechanism to target a single specie. RNAi on hemipterans, Asian citrus psyllid, and glassy-winged sharpshooter show promising results. The psyllid transmits deadly plant-infecting bacterium of citrus trees, Citrus Greening Disease, aka. Huanglongbing. Leafhoppers transmit $X$. fastidiosa bacteria, Pierce's Disease of grapevines. Ingestion of specific dsRNA showed specie specific suppression, and increased mortality. Bioassays of cut plant tissue, or potted seedlings, with 10 to 100ng dsRNA were tested. Trials of 8 cages or seedlings/treatment, with 20 adults, or 50-100 psyllid/tree. Negative Control dsRNA was GFP. Mortality across 12-17 days, began on $5 \mathrm{~d}$ post feeding. Mortality rates varied for dsRNAs from $10-100 \%$. The dsRNAs induced significant insect mortality over controls, and was safely ingested by honey bees, Apis mellifera. RNAi continues to show potential as a means of specific insect pest management.

Field-based high-throughput phenotyping for evaluation of barely yellow dwarf resistance in wheat breeding J. POLAND (1), X. Wang (2), D. Rotenberg (2), A. Laney (2), A. Whitfield (2), M. Ramos (2), A. Fritz (2)

(1) Kansas State University, U.S.A.; (2) Kansas State University, U.S.A.

Rapid and precise assessment of large populations is at the heart of genetic gain plant breeding and statistical power in quantitative genetics. While, the development of next-generation sequencing has enabled a genomics revolution in the world of plant breeding and genetics, the current approaches to collecting phenotypic have seen little advancement over the last century. The development of high-throughput phenotyping (HTP) approaches have the potential to transform the breeding process and accelerate genetic gain. With this vision, we have developed and deployed ground-based HTP platforms and unmanned aerial vehicles (UAV) equipped with a range of sensors and cameras to monitor plant growth and development during the field season. To test these platforms for assessing disease resistance, we evaluated 70 elite breeding lines from the KSU wheat breeding program in 6 reps early planted to attract the aphid vectors of barley yellow dwarf (BYD). Enabled by HTP, a 'case-control' approach was taken with 3 reps insecticide treated to prevent aphid-vectored infection of BYD and 3 reps left untreated. Throughout the growing season we were able to precisely quantify plant stunting, reduced vegetation index and loss of biomass and projected grain yield via the HTP platforms. The implementation of HTP can give breeders the possibility to rethinking current approaches to field-based breeding and open new avenues to rapid development of new, superior performing varieties.

Unraveling the host-pathogen interaction via phenotyping and molecular characterization of resistance—Soybean as a case study S. CIANZIO (1)

(1) Iowa State University, U.S.A.

Plants suffer from many yield deterrents that have direct impacts on humans in terms of food security, and production-income. The interaction of pathogen, environment and host, is one deterrent amenable to genetic manipulation. Host genetic resistance is one of the most effective, efficient and ecologically sustainable means to protect yield. In the presence of pathogens, genetic resistance allows the final expression of yield potential. Soybeans will be used as a case study. I will use examples on how single gene resistance, and quantitative trait resistance impact screening results and the efficiency of breeding for resistant genotypes. The resistance inheritance mechanisms on the plant determines how to devise effective screening protocols and the corresponding scoring results to differentiate among genotypic resistance levels. The breeding challenge common to all resistance inheritance mechanisms, is to select genotypes via screening approaches that will identify resistant genotypes accurately, and repeatable across environments. Correct identification of the resistance genes/genotypes for advancement in the breeding process will result in the release of effective resistant cultivars and germplasms to protect yield. Molecular information to determine/confirm resistance is a tool that has opened new approaches to breeding.

Molecular mechanisms behind the HLB symptom variations and rapid selection for variant citrus plants with greater HLB resistance/tolerance Y. DUAN (1), M. Pitino (1)

(1) USDA-ARS-USHRL, U.S.A.

Huanglongbing (HLB) is a devastating bacterial disease of citrus worldwide. Various HLB symptoms are observed in different species/varieties of citrus plants: from yellow shoots to blotchy mottles on the leaves, and from vein yellowing/vein corky to mosaic on the leaves, etc. These variations of symptoms not only present on individual plants from a variety but also exist on individual branches of an infected plant. Our results indicated that the 
adaptation of the bacterial populations, such as the population dynamics of 'Candidatus Liberibacter asiaticus' (Las), plays an important role in induction of symptoms, and the number of Las prophages/phages and the effectors may contribute to these difference. While the selection of the host plants for the bacterial populations is also critical for symptom expression during disease progression. Based on the severity of HLB symptoms, we divided them into four grades. Using a newly identified biomarker from host plants we were able to correlate HLB symptom severity with different concentrations of the biomarker. Gene expression profiling of different grades of infected leaves rationalized the differentiation based on the biomarker. Based on the variations of the HLB symptoms, the bacterial populations/titers, and the dynamics of the biomarker, we proposed new approaches to select variant citrus plants including bud sports with greater HLB resistance/tolerance along with protocols and criterial for evaluation.

\section{Development of controlled high throughput and user friendly assays for host responses to rice pathogen isolates}

Y. JIA (1)

(1) USDA-ARS Dale Bumpers National Rice Research Center, U.S.A.

Rice sheath blight (SH) disease caused by the soil borne fungus Rhizocotonia solani AG1-IA is a major detrimental disease of rice in the USA and worldwide. The major genes for resistance to $R$. solani have not been identified, while genes providing minor phenotypic effects have been identified in several rice varieties worldwide. SH disease is currently managed with fungicides integrated into different cultural practices. The use of genetic resistance reduces production costs which is a preferred crop protection method. However, monitoring the resistance effect of minor genes is technically challenging because their phenotypic contributions are often masked by confounding factors including plant height, plant type (i.e., tiller angle), and days to heading. In the present study, $102 \mathrm{R}$. solani isolates from commercial rice fields in Arkansas were evaluated in vitro, and the slower growing isolates were identified for subsequent phenotyping analyses. A series of phenotyping methods, detached leaf, mist chamber, microchamber, and field plots with fungal biomass grown on potato dextrose agar plugs, tips of toothpicks, and a corn chop and rye mixture, were successfully used to evaluate genomic regions and candidate genes including an $\mathrm{ABC}$ transporter in rice that are responsible for resisting the infections by $R$. solani; and results will be presented.

Molecular aspects of host pathogen interactions in common bacterial blight in Phaseolus vulgaris caused by Xanthomonas K. Pauls (1), K. Pauls (1), W. Xie (1), T. Smith (1), G. Perry (1), E. Castro (1)

(1) Department of Plant Agriculture, University of Guelph, Canada

Common bacterial blight (CBB), caused by Xanthomonas axonopodis pv. phaseoli and its fuscan variant $X$. fuscans subsp. fuscans, is a damaging disease of common bean throughout the world. Genetic studies have identified a locus associated with the molecular marker SU91 on bean chromosome 8 which confers broad-spectrum resistance to the disease. To examine the genes in the locus in more detail the genomic sequence of the resistant line OAC Rex in the SU91 CBB resistance QTL was compared to the corresponding genome sequence of the susceptible line G19833. This comparison identified a reorganization of a sterol transport gene and the occurrence of additional resistance (R) genes in the OAC Rex genome, which may be associated with resistance. To understand the diversity of the CBB pathogen, single colonies (lines), purified from each of four locally collected bacterial isolates, were tested for symptom development and 7 lines with differential aggressiveness were characterized by genome sequencing. Their genome sizes ranged from 5.32-5.36 Mbp and some genomic rearrangements were observed between the isolates. Differences in candidate virulence factors were identified that may be related to differences in aggressiveness between the bacterial lines through interactions with the promoters of target genes in bean resistance genes in the SU91 QTL region. This information will facilitate breeding bean cultivars with durable CBB resistance.

\section{Phenotyping for resistance to viruses in maize}

M. REDINBAUGH (1), J. Zambrano (2), M. Jones (3), D. Francis (4), R. Louie (3)

(1) USDA-ARS Corn, Soybean and Wheat Quality Research, U.S.A.; (2) INIAP, Ecuador; (3) USDA, ARS CSWQRU, U.S.A.; (4) Ohio State University, U.S.A.

The great strides made in sequence and genotypic analysis in maize have facilitated rapid identification of genes and quantitative trait loci (QTL) in maize, but identifying virus resistance genes and QTL continues to require high efficiency screening protocols that allow identification and evaluation of resistant plants. Over the last 40 years researchers in the USDA, ARS - Ohio State University maize virus research program have used natural infection, leaf rub inoculation (VPI), air brush, backpack sprayer, solid stream protocols, vascular puncture inoculation, and viruliferous insects to (i) screen germplasm collections to identify resistance sources; (ii) identify markers linked to genes or QTLs conferring resistance; and (iii) introgress resistance into elite breeding lines. Mechanical transmission, VPI and insect transmission were used to characterize resistance to each of nine viruses in six virus families in the multiply virus resistant inbred line, Oh1VI. Depending on the virus, dominant, recessive, or additive gene effects were responsible for the resistance observed, and resistance was associated with one to three loci. Major clusters of resistance genes were identified in specific regions of chromosomes 2, 3, 6, and 10. It is unknown whether these QTL clusters contain single or multiple virus resistance genes, but close linkage of resistance loci in this line could facilitate development of virus resistant crops.

Field-based phenomics for stress detection: An overview

J. WHITE (1), M. Newcomb (2), P. Andrade-Sanchez (3)

(1) Arid-Land Agricultural Research Center, Maricopa, AZ, U.S.A.; (2) University of Arizona, Maricopa, AZ, U.S.A.; (3) Agricultural \& Biosystems Engineering, University of Arizona, Maricopa, AZ, U.S.A

Many crop stress and disease responses are best studied in field environments where soil, microclimatic and stress conditions are directly relevant to commercial production. However, evaluating plant populations large enough to permit meaningful genetic analyses presents challenges for accurate phenotyping. In research on drought, heat and to a limited extent, plant diseases, our group in Maricopa, AZ is developing phenotyping systems that use proximal sensing to achieve desired levels of accuracy and throughput. A typical configuration consists of four sets of ultrasonic height sensors, infrared thermometers and multi-band reflectance sensors that are connected to a datalogger operating at $5 \mathrm{~Hz}$ and a GPS that georeferences the sensor data with less than $5 \mathrm{~cm}$ positional error. Tractors and hand carts are used as vehicles. The systems have been deployed in cotton, wheat, oil-seeds, common bean, melons and sunflower. Recognizing multiple limitations of ground vehicles, work is underway with unmanned aerial vehicles and with a gantry cranebased robotic system. Results from cotton, wheat, cantaloupe and common bean are presented to illustrate the multiple options and challenges both in deploying sensors and analyzing the data.

\section{Metatranscriptomics: Principles and Applications for Studying Plant-Pathogen Interactions}

L. GUO (1), L. Ma (2), R. Wick (2), K. Allen (2), K. Vescio (2)

(1) University of Massachusetts, Amherst, U.S.A.; (2) University of Massachusetts, Amherst, U.S.A.

Benefited from low sequencing costs and the rapid advancement in bioinformatics, the next generation sequencing technology has been applied to a wide range of organisms including plants and their pathogens, which has transformed the field of plant pathology. One application of such technology is metatranscriptomics. Capable of simultaneously profiling transcriptomes of multiple species with or without existing genome sequences, metatranscriptomics offers an unprecedented opportunity to study host-pathogen interactions. However, the successful application of this sophisticated technology driven by large quantity of data depends on many factors, including experimental designs, choice of data analysis software and biological interpretation of results etc. In this presentation, we will present an introduction of basic principles, experimental designs of metatranscriptomics and its applications in plant-pathogen interactions. Practically, we will discuss two common data analysis pipelines, one based on reference-guided transcript 
assembly and the other based on de novo transcript assembly. Using examples of two different pathosystems, Fusarium wilt of Arabidopsis (genomic information for both genomes are published) and Basil downy mildew (genomic information is available for neither the host nor the obligate parasite), we will demonstrate the power of metatranscriptomics on identifying key genes and pathways involved in host immunity and pathogen virulence.

RNA-Seq unveils distinct interactions of whitefly with Tomato chlorosis virus and other viruses

N. KAUR (1), D. Hasegawa (2), W. Chen (3), Y. Zheng (3), Z. Fei (3), K. Ling (4), W. Wintermantel (5)

(1) USDA, Salinas, CA, U.S.A.; (2) Boyce Thompson Institute, Ithaca, NY 14853, USA; USDA-ARS, Salinas, CA, USA, U.S.A.; (3) Boyce Thompson Institute, Ithaca, NY 14853, USA, U.S.A.; (4) USDA-ARS, Charleston, SC, USA, U.S.A.; (5) USDA-ARS, Salinas, CA, USA, U.S.A.

Whitefly, Bemisia tabaci, MEAMI, biotype B is a serious agriculture pest that causes crop losses through direct feeding or virus transmission. B. tabaci is highly polyphagous, infests crops worldwide, and rapidly develops resistance to insecticides. To understand how whitefly interacts with semipersistent viruses, RNA-Seq was performed on whiteflies fed on Tomato chlorosis virus (ToCV)-infected tomato for 24, 48, and $72 \mathrm{~h}$. Analysis of transcriptome data between viruliferous and healthy whiteflies revealed $>1,000$ genes regulated in ToCV-whiteflies. Further analysis unveiled significantly different expression of several genes and gene families: cathepsins, glucose-transporters, alpha-glucosidases and some genes from the uric acid pathway. Furthermore, $\sim 380$ large clusters of tandemly duplicated genes with unknown protein functions were found to be influenced in whiteflies by ToCV infection of host plants. Comparison of gene expression changes related to feeding on a persistent virus revealed fewer but distinct differences in gene expression than were observed for the semipersistent virus. These differences may be linked to the different modes (semipersistent-noncirculative and persistent-circulative) of virus transmission. The data will shed light on the molecular relationships involved in whitefly transmission of viruses and lead to new approaches for pest management.

\section{Probing Pseudomonas syringae host interactions using metatranscriptomics}

M. FILIATRAULT (1)

(1) USDA-ARS/Cornell University, U.S.A.

Transcriptome analyses during the interaction of plants and pathogens can be used to provide insights into molecular mechanisms of plant resistance as well as the mechanisms used by bacteria to adapt to hosts and cause disease. We performed a dual in planta RNA-Seq experiment to profile RNA expression in both the plant pathogen Pseudomonas syringae and host before and after effector deployment. P. syringae DC3000 ?hopQ1-1 was syringe infiltrated into Nicotiana benthamiana. Analysis of the RNA-Seq data showed that approximately 2000 P. syringae transcripts displayed differential expression between one hour and six hours post inoculation. We found that as disease progressed bacterial transcripts that encode for siderophores and motility were generally down regulated whereas genes involved in coronatine biosynthesis, alginate production, and the utilization of carbon sources such as fructose, sucrose and maltose were upregulated during infection. We observed that most genes related to Type III secretion system (T3SS) are down regulated in planta between one and six hours, however some components of the T3SS are induced, suggesting that there are other factors involved in the regulation of a subset of the T3SS components. Overall our results support the notion that during disease progression, P. syringae displays increased metabolic activity along with decreased movement and differential regulation of several Type III effectors occurs in planta.

Transcriptomics of a downy mildew-spinach interaction

R. ORNELAS (1), S. Klosterman (2), S. Koike (3), A. Hulse-Kemp (4), L. Derevnina (4), R. Michelmore (4), S. Reyes-Chin-Wo (4), K. Stoffel (4), A. Van Deynze (4)

(1) California State University at Monterey Bay, Monterey, CA, U.S.A.; (2) United States Department of Agriculture ARS, U.S.A.; (3) UC Cooperative Extension, U.S.A.; (4) University of California, Davis, U.S.A.

Downy mildew of spinach is caused by Peronospora effusa, an obligate, plant pathogenic oomycete, and is the most widespread and destructive disease of spinach in California and wherever spinach is grown. Symptomatic leaves display yellow lesions on otherwise dark green leaves, severely limiting their fresh market value. There is a lack of understanding of the susceptible and resistant genetic responses of the plant to $P$. effus $a$, and the genes that are differentially expressed in these two different interactions. In this study, the susceptible and resistant spinach cultivars, Viroflay and Solomon, respectively, were inoculated with $P$. effusa, and control plants were mock-inoculated. The expression of host and pathogen genes was evaluated using RNA sequencing to determine which genes are up- or down-regulated as a result of infection. Initial results revealed significant differences between treatments, including an abundance of plant defense-related genes that were differentially expressed. Additional analyses underway to uncover genes of P. effusa expressed in planta will be discussed. The results of this work are anticipated to provide insights into how this biotrophic pathogen infects the plant, how the plant responds genetically, and information useful to spinach breeders and pathologists.

Transcriptome analysis of tanoak's mechanisms of innate and phosphite-induced resistance to Phytophthora ramorum K. HAYDEN (1), C. Eyre (2), P. Croucher (2), S. Schechter (2), J. Wright (3), M. Garbelotto (4)

(1) Royal Botanic Garden Edinburgh, Edinburgh, United Kingdom; (2) University of California, Berkeley, Berkeley, CA, U.S.A.; (3) USDA Forest Service Pacific Southwest Research Station, U.S.A.; (4) University of California, Berkeley, U.S.A.

Phosphite compounds have been used in the control of sudden oak death but their precise mode of action is not fully understood. To study the action of phosphite compounds in the context of naturally occurring host resistance, we first identified open-pollinated family groups that carried resistance. Multiple inoculations were performed on previously unchallenged members of these families, half of which had been treated with phosphites. We examined gene expression during the disease response in phosphite-treated, resistant hosts (in which the treatment worked as expected); in phosphitetreated but susceptible hosts (in which phosphite was not effective nor was there innate resistance); and in untreated susceptible and resistant trees. Tanoak families differed in the presence of innate resistance and in the effectiveness of phosphite treatment. There were 9705 genes that were differentially expressed between untreated resistant trees and untreated susceptible trees. There were 7 genes differentially expressed in the same comparison between susceptible and resistant phosphite-treated trees. Our results demonstrate the differences in mode of action of phosphite compounds from innate resistance, and an intriguing lack of difference in gene expression between phosphite-treated trees, whether diseased or apparently healthy.

\section{Initial epidemic conditions and long-distance spread of disease}

\section{Mundt (1)}

(1) Oregon State University, OR, USA

A simple model based on inverse power law dispersal describes accelerating, instantaneous velocities of epidemics caused by pathogens with 'fat-tailed' dispersal kernels both in experimental field plots with wheat stripe rust, as well as for plant and animal epidemics at the continental scale. Disease spread has been found to be independent of spatial scale of study, and proportional to the size of the epidemic outbreak. Coupled with our studies of landscape heterogeneity on wheat stripe rust epidemics, this simple models suggests highly local deposition that makes disease increase largely independent of disease levels in other parts of the population, but with extended "fat tails" that result in an accelerating epidemic front. An implication of such dispersal patterns is that epidemic spread will be determined largely by initial epidemic conditions. This has been confirmed experimentally through field studies of wheat stripe rust. The degree of epidemic spread was determined by the degree of host susceptibility in the outbreak focus, rather than by the degree of susceptibility in the remainder of the plots. Further, culling of outbreak foci showed no effect on epidemic spread unless implemented early in the first generation of secondary spread, and size of ring-culls had no apparent impact on epidemic spread. 
Rapid selection and opportunities for restoration of laurel wilt tolerant Persea species

J. SMITH (1), E. Jokela (1)

(1) University of Florida, Gainesville, FL, U.S.A.

In little more than a decade, laurel wilt caused by Raffaelea lauricola (vectored by Xyleborus glabratus) has spread to nine U.S. states, killing hundreds of millions of redbay (Persea borbonia) trees, altering ecosystems and threatening worldwide avocado production. Typically, ambrosia beetles and their fungal symbionts are not tree killers. LW is unique in that the symbiont of X. glabratus is highly virulent to host trees. Current efforts to manage LW focus on systemic fungicides, insect repellents, sanitation. Naturally occurring forests with high mortality ( $>95 \%)$ form LW have been explored for persistent survivor trees. Propagation and subsequent disease screening have been carried out leading to the identification of disease tolerant redbay clones. Mechanisms of tolerance appear to be associated with reduced tylosis and reduced disruption of vascular function. Seedling populations from tolerant clones have been genotyped and are being phenotyped for tolerance to assist restoration efforts. Future research will focus on genomic analyses as well as examinations of how phylogeography influences host susceptibility within the Lauraceae. 